\title{
Discovery and Validation of a Compound to Target Ewing's Sarcoma
}

\author{
Ellie Esfandiari Nazzaro ${ }^{1,{ }^{\dagger}}$, Fahad Y. Sabei ${ }^{1,2,+} \mathbb{1}$, Walter K. Vogel ${ }^{1} @$, Mohamad Nazari ${ }^{1}$, Katelyn S. Nicholson ${ }^{3}$, \\ Philip R. Gafken ${ }^{4}$, Olena Taratula ${ }^{1}$, Oleh Taratula ${ }^{1, *} \mathbb{C}$, Monika A. Davare ${ }^{3,5, *}$ and Mark Leid ${ }^{1,6, \neq}$ \\ 1 Departments of Pharmaceutical Sciences, College of Pharmacy, Oregon State University, \\ Corvallis, OR 97331, USA; ellie.esfandiari@gmail.com (E.E.N.); fsabei@jazanu.edu.sa (F.Y.S.); \\ walter.vogel@oregonstate.edu (W.K.V.); nazzaromj@gmail.com (M.N.); olena.taratula@oregonstate.edu (O.T.); \\ mark.leid@wsu.edu (M.L.) \\ 2 Department of Pharmaceutics, College of Pharmacy, Jazan University, Jazan 88723, Saudi Arabia \\ 3 Division of Pediatric Hematology \& Oncology, Department of Pediatrics, Oregon Health \& Science University, \\ Portland, OR 97239, USA; nickatel@ohsu.edu \\ 4 Proteomics \& Metabolomics Shared Resource, Fred Hutchinson Cancer Research Center, \\ Seattle, WA 98109, USA; pgafken@fredhutch.org \\ 5 Papé Pediatric Research Institute, Oregon Health \& Science University, Portland, OR 97239, USA \\ 6 Department of Integrative Biosciences, Oregon Health \& Science University, Portland, OR 97239, USA \\ * Correspondence: oleh.taratula@oregonstate.edu (O.T.); davarem@ohsu.edu (M.A.D.) \\ + These authors contributed equally to this work. \\ $\ddagger$ Current address: Department of Pharmaceutical Sciences, College of Pharmacy and Pharmaceutical Sciences, \\ Washington State University, 412 E. Spokane Falls Blvd., PBS 130, Spokane, WA 99202, USA.
}

Citation: Esfandiari Nazzaro, E.; Sabei, F.Y.; Vogel, W.K.; Nazari, M.; Nicholson, K.S.; Gafken, P.R.; Taratula, O.; Taratula, O.; Davare, M.A.; Leid, M. Discovery and Validation of a Compound to Target Ewing's Sarcoma. Pharmaceutics 2021, 13, 1553. https://doi.org/10.3390/

pharmaceutics13101553

Academic Editor: Twan Lammers

Received: 12 August 2021

Accepted: 15 September 2021

Published: 24 September 2021

Publisher's Note: MDPI stays neutral with regard to jurisdictional claims in published maps and institutional affiliations.

Copyright: (C) 2021 by the authors. Licensee MDPI, Basel, Switzerland. This article is an open access article distributed under the terms and conditions of the Creative Commons Attribution (CC BY) license (https:// creativecommons.org/licenses/by/ $4.0 /)$.

\begin{abstract}
Ewing's sarcoma, characterized by pathognomonic t $(11 ; 22)$ (q24; q12) and related chromosomal ETS family translocations, is a rare aggressive cancer of bone and soft tissue. Current protocols that include cytotoxic chemotherapeutic agents effectively treat localized disease; however, these aggressive therapies may result in treatment-related morbidities including second-site cancers in survivors. Moreover, the five-year survival rate in patients with relapsed, recurrent, or metastatic disease is less than $30 \%$, despite intensive therapy with these cytotoxic agents. By using high-throughput phenotypic screening of small molecule libraries, we identified a previously uncharacterized compound (ML111) that inhibited in vitro proliferation of six established Ewing's sarcoma cell lines with nanomolar potency. Proteomic studies show that ML111 treatment induced prometaphase arrest followed by rapid caspase-dependent apoptotic cell death in Ewing's sarcoma cell lines. ML111, delivered via methoxypoly(ethylene glycol)-polycaprolactone copolymer nanoparticles, induced dose-dependent inhibition of Ewing's sarcoma tumor growth in a murine xenograft model and invoked prometaphase arrest in vivo, consistent with in vitro data. These results suggest that ML111 represents a promising new drug lead for further preclinical studies and is a potential clinical development for the treatment of Ewing's sarcoma.
\end{abstract}

Keywords: Ewing's sarcoma; chemotherapy; cancer; ML111; drug discovery; nanoparticle drug delivery; high-throughput screening

\section{Introduction}

Ewing's sarcoma, a small and round blue-cell malignancy arising from bone or soft tissue, most commonly affects children and adolescent patients. Ewing's sarcoma is a rare aggressive cancer, posing substantial clinical challenges, and while prognoses have improved for young patients or patients with localized disease, outcomes for metastatic or relapsed disease remain dire [1,2]. Currently, standard treatment includes multimodal strategies with combinations of chemotherapy (vincristine, doxorubicin, cyclophosphamide, and ifosfamide), surgery, and radiation [3,4]. Targeted therapies for Ewing's sarcoma have not 
advanced to the clinic despite precise knowledge of the etiology of the disease for nearly 30 years.

Up to $90 \%$ of Ewing's sarcoma cases result from reciprocal chromosomal translocation involving the EWSR1 (EWS) gene, which encodes an RNA-binding protein, and the gene encoding Friend leukemia virus integration 1 (FLI1), a member of the E26 transformationspecific (ETS) family of transcription factors, generating the pathognomonic EWS-FLI1 chimeric fusion protein. EWS-FLI1 and related fusion proteins contain the amino-terminus of EWSR1 harboring a strong transcriptional activation domain fused in frame with the carboxy terminus of FLI1, which contributes a highly promiscuous ETS-type DNA binding domain [5-7]. EWS-FLI1 and related fusion proteins regulate the expression of a large network of genes and dysregulation of this network underpins Ewing's sarcoma pathogenesis, at least in part [8-10]. Notably, ectopic expression of EWS-FLI1 confers oncogenic and/or tumorigenic properties in permissive cell types [5,11,12].

EWS-FLI1 and related chimeric proteins are not expressed in untransformed cells; thus, Ewing's sarcoma should be highly amenable to precision medicine-based approach [13]. However, currently there are no FDA-approved, molecularly targeted treatments for Ewing's sarcoma. Efforts are underway to discover and validate pharmacological or other therapeutic approaches that directly downregulate EWS-FLI1 or target downstream or synthetic lethal vulnerabilities generated by this fusion oncoprotein. Agents being investigated in the relapsed Ewing's sarcoma setting include epigenetic therapies (e.g., inhibitors of lysine-specific demethylase 1 (LSD1), histone deacetylases, and bromodomain-containing proteins), inhibitors of various downstream components of the EWS-FLI1 transcriptional network (TKI-216), agents that bind to DNA and disrupt processing of DNA by multiple pathways (e.g., plicamycin and trabectedin), CD99 targeting agents (clofarabine/cladribine and anti-CD99 antibodies), an anti-insulin-like growth factor receptor antibody (Ganitumab), and others [3]. Even if novel, molecularly targeted agents were to become available, the nearly inevitable development of therapeutic resistance to targeted agents necessitates a diverse or expanded pharmacological pipeline for potential second-line use.

Here, we describe results from a forward pharmacological screen that resulted in the identification of a compound, ML111, that potently inhibits the viability of Ewing's sarcoma cells in vitro and in vivo. Chemical, biochemical, cell biological, and animal model data presented herein suggest that this small molecule has the potential to be an effective anti-tumor agent in the treatment of Ewing's sarcoma.

\section{Materials and Methods}

\subsection{Chemicals}

2-amino-4-(3-methoxyphenyl)-4H-benzo[h]chromene-3-carbonitrile (ML111; PubChem SID 3323178) was purchased from ChemBridge (San Diego, CA, USA, \#5307066) or synthesized according to the previous literature [14]. mPEG-PCL (methoxy poly(ethylene glycol)-b-poly( $\varepsilon$-caprolactone), MW: 5 k-10 k) was obtained from Advanced Polymer Materials Inc. (Montreal, QC, Canada), and SiNc was obtained (silicon 2,3-naphthalocyanine bis(trihexylsilyloxide)) from Sigma-Aldrich (Milwaukee, WI, USA).

\subsection{Primary Antibodies}

Antibodies to caspase 3 (\#14220), CDC20 (\#14866), cyclin B1 (\#12231), GAPDH (\#5174), histone H3 (\#4499), phospho-Ser10-histone H3 (pH3 ${ }^{\text {Ser10 }}$,\#53348), PARP (\#9532), $\alpha$-Tubulin (\#2125, used for immunoblot analyses), and $\alpha$-Tubulin (\#3873, used for immunocytochemistry) were obtained from Cell Signaling (Danvers, MA, USA). Antibody to FLI1 (ab15289) was obtained from Abcam (Waltham, MA, USA).

\subsection{Cell Lines and Cell Culture}

Most Ewing's sarcoma cell lines were kind gifts from the laboratory of Dr. Marc Ladanyi at Memorial Sloan Kettering Cancer Center. All other cell lines were acquired from ATCC (Manassas, VA, USA). SK-ES-1 and SK-OV-3 were cultured in McCoy's 5A 
Medium (Corning, Glendale, AZ, USA). SK-N-MC, MDA-MB-231, and HEK293 cells were maintained in Minimum Essential Medium (Corning). HCC78, CHP100, A-673, TC-71 and TC-32, H3122, ES-2, and H460 cells were grown in RPMI 1640 (Thermo Fisher Scientific, Waltham, MA, USA). Human umbilical vein endothelial cells (HUVECs) were cultured in supplemented Medium 200, according to the manufacturer's instructions. All cell lines were also maintained in 1\% penicillin/streptomycin (Thermo Fisher Scientific, Waltham, MA, USA), 4 mM glutamine, and 10\% Fetal Bovine Serum (FBS, R\&D Systems, Minneapolis, MN, USA), except for SK-ES-1 cells, which were cultured in media containing 15\% FBS, and the cells were maintained at $37^{\circ} \mathrm{C}$ in a humidified incubator with $5 \% \mathrm{CO}_{2}$.

\subsection{High-Throughput Screening}

SK-ES-1 cells were seeded at $1.0 \times 10^{4}$ cells /well in 384-well tissue culture plates for HTS studies. After $24 \mathrm{~h}$, compounds or controls were added by using a Sciclone ALH3000 Liquid Handler (Perkin Elmer, Waltham, MA, USA), and incubations were conducted for an additional $48 \mathrm{~h}$. The primary screen was conducted using $10 \mu \mathrm{M}$ compound, and all compounds were tested in triplicate. Follow-on studies using Ewing's sarcoma and non-Ewing's sarcoma cell lines were conducted similarly, with the exception that a HPD300 dispenser (HP Inc., Palo Alto, CA, USA) was used for liquid handling, and wells contained $0.5 \times 10^{4}$ cells. Cell viability was measured using a luciferase-based reagent, CellTiter-Glo (Promega, Madison, WI, USA). Compounds that inhibited Ewing's sarcoma cell growth by $85 \%$ were considered "hits", and the growth inhibitory activity of these compounds was confirmed in secondary screens using a full range of compound concentrations. Doseresponse curves were fit and analyzed using Prism 6.0 (GraphPad Software, San Diego, CA, USA). DMSO and bortezomib were used as negative and positive controls, respectively, and the Z-factor [15] for each screening plate $\left(Z^{\prime}\right)$ was in the range of $0.5-0.9$, validating the high-throughput screening assay.

\subsection{Imaging Caspase 3/7 Activation}

SK-ES-1 cells were seeded at a density of 8000 cells per well in 96-well plate. After $20 \mathrm{~h}$ the cells were treated in triplicate with ML111 (50 nM), cabozantinib (250 nM), or vehicle control (0.05\% DMSO). CellEvent Caspase-3/7 Green Detection Reagent (Thermo Fisher Scientific, Waltham, MA, USA), a fluorogenic substrate for activated caspase 3/7, was added to the same wells following the manufacturer's protocol, and the cells were live imaged by using the Incucyte (Sartorius, Bohemia, NY, USA) imaging system with data capture set for every $30 \mathrm{~min}$. The CellEvent reagent is intrinsically non-fluorescent in healthy cells because the DEVD peptide inhibits the ability of the fluorescent dye to bind DNA. The activation of caspase $3 / 7$ in apoptotic cells results in cleavage of the DEVD peptide, enabling the dye to bind DNA and produce a green, fluorogenic response. Cells that activate caspase $3 / 7$ emit green fluorescence and are identified as unique objects by the software. The relative number of cells that activate caspase $3 / 7$ was quantified by using the built-in Incucyte image analysis tools. Imaging was suspended after $23 \mathrm{~h}$.

\subsection{Annexin V Staining}

Cells were stained with FITC-Annexin V and propidium iodide by using a kit (product number V13242) from Thermo Fisher Scientific (Waltham, MA, USA), according to the manufacturer's instructions. Briefly, SK-N-MC $\left(2 \times 10^{6}\right)$ cells were cultured in a $25 \mathrm{~cm}^{3}$ flask overnight, after which cells were exposed to ML111 (100 nM) or vehicle control (0.1\% DMSO) at predetermined time points. Cells were harvested, washed with cold Dulbecco's phosphate buffered saline, and collected by centrifugation. Pelleted cells were resuspended in $100 \mu \mathrm{L}$ of annexin binding buffer and stained with $5 \mu \mathrm{L}$ of FITC-annexin V and $1 \mu \mathrm{L}$ of propidium iodide for $15 \mathrm{~min}$ at room temperature and in the dark. Additional annexin binding buffer $(400 \mu \mathrm{L})$ was added; samples were kept on ice before analysis by flow cytometry using a BD Accuri C6 flow cytometer (BD Biosciences, San Jose, CA, USA). Flow data were analyzed using FlowJo software (FlowJo LLC, Ashland, OR, USA). 


\subsection{Z-VAD-FMK Rescue Experiments}

SK-N-MC cells, $1 \times 10^{4}$ cells/well in a 96-well plate, were treated with the cellpermeable, irreversible pan-caspase inhibitor Z-VAD-FMK (50 $\mu \mathrm{M}$; APExBIO, Houston, TX, USA), or vehicle (DMSO, final concentration of $0.1 \%$ ) for $2 \mathrm{~h}$ prior to addition of ML111 (100 nM) or vehicle. The cells were treated with ML111 or vehicle for an additional $24 \mathrm{~h}$. Cell viability was determined by using the Calcein AM assay (Corning, Glendale, AZ, USA), as described previously [16].

\subsection{Immunoblot Analyses}

Cells $\left(2 \times 10^{6}\right)$ were dispersed on $10 \mathrm{~cm}$ plates and incubated overnight. The medium was removed, and the cells were incubated with freshly diluted vehicle or ML111 at various concentrations for various times. Cells were washed with ice-cold PBS (pH 7.4) and scraped into ice-cold PBS and centrifuged $(800 \times g)$ for $5 \mathrm{~min}$ at $4{ }^{\circ} \mathrm{C}$. Cell pellets were lysed in

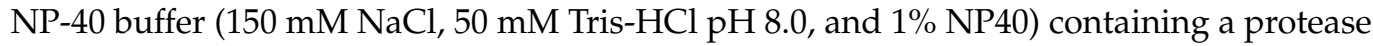
inhibitor cocktail, and protein concentrations in the lysates were determined by using the BCA assay (Thermo Fisher Scientific, Waltham, MA, USA). Lysates (20-30 $\mu \mathrm{g}$ of total protein) were combined with the sample buffer and boiled for $10 \mathrm{~min}$ prior to separation by polyacrylamide gel electrophoresis.

Gels were blotted to nitrocellulose membranes, which were then blocked by using an Odyssey PBS Blocking Buffer (LI-COR Biosciences, Lincoln, NE, USA) prior to incubation with primary antibodies, following the manufacturer's instructions. Immunoreactive bands were detected by use of fluorescently tagged secondary antibodies: goat anti-rabbit IRDye $800 \mathrm{CW}$ and IR Dye $680 \mathrm{CW}$ goat anti-mouse (LI-COR and both at 1:5000 dilution). A LI-COR Odyssey scanner was used to visualize, quantify, and analyze the intensities of resultant fluorescent bands using ImageStudio (version 2.1, LI-COR Biosciences, Lincoln, NE, USA).

\subsection{Histology, Immunohistochemistry, and Slide Evaluation}

Tumor tissues were fixed for $2 \mathrm{~h}$ at $4{ }^{\circ} \mathrm{C}$ in fresh $4 \%$ paraformaldehyde (Electron Microscopy Sciences, Hatfield, PA, USA) in PBS. Fixed tumors were washed with ice-cold PBS and incubated in PBS overnight at $4{ }^{\circ} \mathrm{C}$ and then transferred to $20 \%$ sucrose in PBS for 24-48 $\mathrm{h}$ prior to embedding (Tissue-Tek O.C.T. Compound, Sakura Finetek, Torrance, CA, USA). Tissues were sectioned using Leica CM 1850 UV Cryostat (Leica Biosystems, Buffalo Grove, IL, USA). Sections $(8-10 \mu \mathrm{m})$ were washed with PBS and endogenous peroxidase was inactivated by incubating the sections with $3 \%$ hydrogen peroxidase for 20 min prior to blocking in FBS. Sections were incubated with anti-pH3 $3^{\text {Ser10 }}$ antibody at $4{ }^{\circ} \mathrm{C}$ overnight. Sections were trice washed with PBS and incubated with a biotinylated secondary antibody (IDSTM003, ID Labs, London, ON, Canada) for $2 \mathrm{~h}$, followed by incubation with avidinhorseradish peroxidase (HRP) (IDSTM003, ID Labs) for $20 \mathrm{~min}$. The slides were stained with 3,3'-diaminobenzidine (DAB; Vector Laboratories, Burlingame, CA, USA), according to the manufacturer's protocol. A counterstaining with hematoxylin (MilliporeSigma, Burlington, MA, USA) for $10 \mathrm{~s}$ was performed at the end of the staining. The sections were mounted by using Aquatex (MilliporeSigma, Burlington, MA, USA) and visualized using a Zeiss Axio Imager Z1 microscope. Qualitative and quantitative analyses of sections were evaluated by five different slides in a blinded fashion.

\subsection{Immunocytochemistry}

SK-N-MC cells were grown on glass coverslips (VWR, Radnor, PA, USA) in complete medium and treated with ML111 (25 nM) or DMSO (0.1\%) for $24 \mathrm{~h}$. Cells were fixed (ice-cold methanol), rehydrated with PBS, and blocked with 10\% FBS (R\&D Systems) and incubated with anti-pH3 ${ }^{\mathrm{Ser} 10}$ and anti- $\alpha$-Tubulin, each at a dilution of 1:500. The cells were counterstained with 4',6-diamidino-2-phenylindole (DAPI, Thermo Fisher Scientific, Waltham, MA, USA) and visualized by using a Zeiss Axio Imager Z1 microscope (Carl 
Zeiss, White Plains, NY, USA) with appropriate filters and a $63 \times$ oil-immersion objective. Color images were digitally overlaid using the Zeiss AxioVs40 software v.4.8.2.0.

\subsection{Microtubule Polymerization Assay}

Cell-free tubulin polymerization assays were conducted according to the manufacturer's instructions (BK006P; Cytoskeleton, Inc., Denver, CO, USA). Briefly, tubulin proteins ( $>99 \%$ purity) were suspended in G-PEM buffer ( $80 \mathrm{mM}$ PIPES, pH 6.9, $2 \mathrm{mM} \mathrm{MgCl}$, $0.5 \mathrm{mM}$ EGTA, $1 \mathrm{mM}$ GTP) with or without paclitaxel (10 $\mu \mathrm{M}$; Cytoskeleton, Inc., Denver, CO, USA), colchicine (10 $\mu \mathrm{M}$; Sigma-Aldrich, St. Louis, MO, USA), and ML111 (0.1 and $1.0 \mu \mathrm{M})$ in a 96-well plate, and the absorbance was measured continuously at $340 \mathrm{~nm}$ for 60 min (Synergy multimode microplate reader, BioTek, Winooski, VT, USA).

\subsection{Cell Cycle Analysis}

SK-N-MC cells $\left(0.9 \times 10^{6}\right)$ were plated in $6 \mathrm{~cm}$ dishes and incubated overnight. The medium was exchanged, and the cells were treated with $100 \mathrm{nM}$ ML111 or vehicle $(0.1 \%$ DMSO). Cells were harvested at the times specified for each experiment, washed with PBS, fixed in $70 \%$ ice-cold ethanol, and stored overnight at $-20{ }^{\circ} \mathrm{C}$. Fixed cells were washed in PBS and resuspended in staining solution, $0.1 \mathrm{mg} / \mathrm{mL}$ propidium iodide containing $0.1 \mathrm{mg} / \mathrm{mL}$ ribonuclease A, and incubated for $30 \mathrm{~min}$ prior to DNA content analysis using a Cytomics FC 500 flow cytometer (Beckman Coulter, Indianapolis, IN, USA) using instrument software CXP 2.2.

\subsection{Effect of ML111 on SK-N-MC Cell Proteomics}

\subsubsection{Sample Preparation}

SK-N-MC cells were treated with $100 \mathrm{nM}$ ML111 for $1.5-24 \mathrm{~h}$ or vehicle (0.1\% DMSO). Treated cells were trice washed with ice-cold PBS to remove culture media and nonadherent cells. Adherent cells were collected in ice-cold PBS, pelleted at $1000 \times g$, and frozen in liquid $\mathrm{N}_{2}$. Frozen cell pellets were thawed in 5 volumes of lysis buffer: $4 \%$ SDS, $50 \mathrm{mM}$ HEPES, pH 8, $10 \mathrm{mM}$ DTT, $1 \mathrm{mM}$ EDTA, $0.1 \mathrm{mM}$ PMSF, $1 \mu \mathrm{g} / \mathrm{mL}$ pepstatin A, $5 \mu \mathrm{g} / \mathrm{mL}$ leupeptin, and $10 \mu \mathrm{M} \mathrm{E64}$; the resulting lysate was sonicated and incubated at $75^{\circ} \mathrm{C}$ with shaking at $1400 \mathrm{rpm}$ for $15 \mathrm{~min}$ and clarified by centrifugation. The SDS was then removed by ultrafiltration (Amicon Ultra-15, 3000 MWCO, MilliporeSigma, Burlington, MA, USA) and exchanged into Lys-C digestion buffer: $7.5 \mathrm{M}$ urea, $20 \mathrm{mM}$ HEPES, and $\mathrm{pH} 8$ (final dilution factor 1:125,000). The resulting protein extracts were reduced with the addition of $10 \mathrm{mM}$ TCEP and incubated for $1 \mathrm{~h}$ at $55^{\circ} \mathrm{C}$, then alkylated by the addition of $20 \mathrm{mM}$ 2-chloroacetamide and incubated for $30 \mathrm{~min}$ at room temperature. Lys-C (Promega, Madison, WI, USA) was added at a ratio of 40:1 (extract: protease) and incubated for $4 \mathrm{~h}$ at $37^{\circ} \mathrm{C}$ with mixing. After diluting urea to $1 \mathrm{M}$ with $20 \mathrm{mM}$ HEPES, $\mathrm{pH} 8$, trypsin (Promega, Madison, WI, USA) was added at a ratio of 50:1 (extract: protease) and incubated for $15 \mathrm{~h}$ at $37^{\circ} \mathrm{C}$ with mixing. Digests were acidified with TFA to $\mathrm{pH}<2$ and desalted on Oasis HLB $3 C \mathrm{C}$ cartridges (Waters, Milford, MA, USA). An aliquot of each digest (35 $\mu \mathrm{g}$ of protein) was labeled with one of six unique isobaric tags (TMTsixplex, \#90061, Thermo Fisher Scientific, Waltham, MA, USA) in $35 \mathrm{mM}$ triethylammonium bicarbonate, 29\% acetonitrile, for $1 \mathrm{~h}$ at RT, then quenched with the addition of $0.27 \%$ hydroxlamine for $15 \mathrm{~min}$ at RT. The samples were acidified with TFA, combined, desalted on Oasis HLB 3CC cartridges, and dried by vacuum centrifugation.

\subsubsection{Basic Reverse-Phase Chromatography}

The combined sample was resuspended in $200 \mu \mathrm{L}$ total volume of 5/95\% $(v / v)$ acetonitrile/10 $\mathrm{mM}$ aqueous ammonium bicarbonate, $\mathrm{pH} 8$ (buffer A), and loaded on to a Zorbax Extend-C18 column $(2.1 \times 150 \mathrm{~mm}, 5 \mu \mathrm{m}$ particle size, $\mathrm{p} / \mathrm{n}$ 773700-902, Agilent (Santa Clara, CA, USA) for basic reverse-phase fractionation. The sample was eluted from the column at a flowrate of $250 \mu \mathrm{L} / \mathrm{min}$ with a $1-40 \%$ gradient of $90 / 10 \%(v / v)$ acetonitrile $/ 5 \mathrm{mM}$ aqueous ammonium bicarbonate, $\mathrm{pH} 8$ (buffer B) over $50 \mathrm{~min}$, followed by $40-95 \%$ buffer 
B over $5 \mathrm{~min}$, and then held at $95 \%$ buffer B for an additional $5 \mathrm{~min}$. Eluting peptides were monitored by absorbance at $210 \mathrm{~nm}$, and $250 \mu \mathrm{L}$ fractions were collected and combined by concatenation into 20 pools. The pools were subsequently taken to near-dryness by vacuum centrifugation and brought up to $20 \mu \mathrm{L}$ in $2 / 98 \%(v / v)$ acetonitrile $/ 0.1 \%$ aqueous formic acid in preparation for LC-MS analysis.

\subsubsection{Mass Spectrometry}

Sample pools were analyzed on an EASY-nLC 1000 nanoflow LC-coupled Orbitrap Fusion mass spectrometer (Thermo Fisher Scientific, San Jose, CA, USA). The LC system was configured with a PepMap RSLC EasySpray column $(75 \mu \mathrm{m}$ ID $\times 50 \mathrm{~cm}, 2 \mu \mathrm{m}$ particle size, $100 \AA$ pore size, Thermo Fisher Scientific, San Jose, CA, USA) and maintained at $40{ }^{\circ} \mathrm{C}$ during operation. Diluted peptide samples were loaded directly onto the column and eluted with a $2-5 \%$ gradient of acetonitrile in $0.1 \%$ aqueous formic acid from over $5 \mathrm{~min}$, then to $30 \%$ over $180 \mathrm{~min}$, then to $50 \%$ over $10 \mathrm{~min}$, and held at $50 \%$ for $2 \mathrm{~min}$ followed by a 2 min gradient to $90 \%$ and held at $90 \%$ for $10 \mathrm{~min}$, all at a flow rate of $300 \mathrm{~nL} / \mathrm{min}$. Eluting peptides were ionized by electrospray using an EASY-IC source operated at $2.1 \mathrm{kV}$ in positive-ion mode. Data-dependent analysis (DDA) used the highresolution Orbitrap mass analyzer for both MS (precursor ion scans) and MS/MS analysis (tandem mass scans).

MS spectra were recorded in the Orbitrap over a range of 350-1500 $\mathrm{m} / \mathrm{z}$ at a resolution of 120,000 (fwhm, $m / z$ 200) and AGC setting of 400,000 ions and a maximum injection time of $50 \mathrm{~ms}$. Monoisotopic precursor ions (instrument MIPS program) of charge state 2-7 that met a minimum signal intensity of 5000 were selected for MS/MS analysis. Ions meeting these criteria, within a mass tolerance of $10 \mathrm{ppm}$, were then dynamically excluded from reanalysis for $30 \mathrm{~s}$. The selected ions were isolated $(1.2 \mathrm{~m} / \mathrm{z}$-wide window) by the quadrupole and subjected to higher-energy collisional dissociation (HCD) at a normalized collision energy of $40 \%$. MS2 spectra, with first mass $100 \mathrm{~m} / \mathrm{z}$, were recorded in the Orbitrap mass analyzer at a resolution of 15,000 ( $\mathrm{fwhm}, \mathrm{m} / \mathrm{z} 200$ ) and AGC set to 50,000 ions for a maximum ion injection time of $160 \mathrm{~ms}$. MS spectra were recorded in the Orbitrap over a range of 350-1500 m/z at a resolution of 120,000 (fwhm, $\mathrm{m} / \mathrm{z} 200$ ) and AGC setting of 400,000 ions and a maximum injection time of $50 \mathrm{~ms}$. Monoisotopic precursor ions (instrument MIPS program) of charge state 2-7 that met the minimum signal intensity of 5000 were selected for MS/MS analysis. Ions meeting these criteria, within a mass tolerance of $10 \mathrm{ppm}$, were then dynamically excluded from reanalysis for $30 \mathrm{~s}$. The selected ions were isolated $(1.2 \mathrm{~m} / \mathrm{z}$-wide window) by the quadrupole and subjected to higherenergy collisional dissociation (HCD) at a normalized collision energy of $40 \%$. MS2 spectra, with first mass $100 \mathrm{~m} / z$, were recorded in the Orbitrap mass analyzer at a resolution of 15,000 (fwhm, $m / z$ 200) and AGC set to 50,000 ions for a maximum ion injection time of $160 \mathrm{~ms}$.

\subsubsection{Data Analysis and Protein Quantification}

A Proteome Discoverer (version 2.2.0.388, Thermo Fisher Scientific, San Jose, CA, USA) was used to combine instrument raw data files and used to search a combined Uniprot Reference Sequence UP000005640 human protein database (26 May 2018, 73,112 entries) and the CRAP contaminant database (68 entries) [17] for matches relative to the tandem mass spectra by using Sequest HT [18]. The search parameters were set for cleavage by trypsin, allowing up to two missed cleavage sites. The mass tolerances were $10 \mathrm{ppm}$ for precursor and 0.6 Da for fragment ions. Oxidation on methionine, carbamidomethylation on cysteine, acetylation of the protein amino terminus, and TMT-tag modification of lysine and amino terminus were permitted variable modifications. Percolator [19] was used to filter peptide-spectrum matches against a decoy database to assign a false discovery rate (FDR) to peptide-spectrum matches, and protein identifications required minimum (FDR $<1 \%$ ) peptide-spectrum matches and a separately calculated protein-level FDR of $<1 \%$. Protein matches to the cRAP database were filtered out of the results. Reporter 
ions from unique and razor peptides were quantified from HCD MS2 scans by using an integration tolerance of $20 \mathrm{ppm}$ with the most confident centroid setting.

\subsection{Preparation of ML111-Based Nanoparticles (ML111-NP)}

Nanoparticles loaded with ML111 were prepared via a modified solvent evaporating method [20]. Briefly, $1 \mathrm{~mL}$ of mPEG-PCL (40-160 mg) in acetone was added to an equal volume of ML111 (4.5 mg, also in acetone) followed by the addition of $2 \mathrm{~mL}$ of aqueous dextrose solution (5\%). The mixture was stirred for $30 \mathrm{~s}$ to obtain a homogenous solution and was left overnight to allow evaporation of the organic solvent. The resulting solution was centrifuged at $5000 \mathrm{rpm}$ for $5 \mathrm{~min}$, and the supernatant was filtered through a $0.2 \mu \mathrm{m}$ nylon filter in order to obtain a clear nanoparticle solution. For fluorescence visualization, the near-infrared (NIR) dye (silicon 2,3-naphthalocyanine bis(trihexylsilyloxide), SiNc, $0.2 \mathrm{mg} / \mathrm{mL}$ ) was co-encapsulated within ML111-NP, as previously described [20]. Coencapsulation with SiNc allowed evaluation of the body distribution of nanoparticles at predetermined time points using a Pearl Impulse Small Animal Imaging System (LI-COR Biosciences, Lincoln, NE, USA). Mice were euthanized after the completion of the study, and tissues were harvested for ex vivo imaging in order to evaluate the accumulation of the nanoparticles in individual organs and in the xenograft [20].

\subsection{Characterization of ML111-Based Nanoparticles}

2.15.1. In Vivo Assessment of the Toxicity of ML111-NP

Swiss Webster mice (4-6 weeks old; Charles River Laboratories, Wilmington, MA, USA) were randomly separated into three groups five mice receiving ML111-NP, emptymPEG-PCL-NP, and 5\% dextrose, respectively. Intravenous injections (150-200 $\mu \mathrm{L}$ volume) were based on body weight in order to ensure identical doses of polymer $(680 \mathrm{mg} / \mathrm{kg}$ of mPEG-PCL) and ML111 (15 mg/kg) to all mice. Mice were dosed three times per week for three weeks. After treatment and euthanasia, blood samples were collected and submitted for complete blood chemistry analyses (IDEXX Veterinary Services; Portland, OR, USA). Serum biochemistry evaluations addressed the following organ toxicities: kidney, blood urea nitrogen level, and creatinine; heart and creatine kinase; and liver, alanine transaminase, aspartate transaminase, and alkaline phosphate. Toxicities affecting the blood were assessed by conducting complete blood counts and levels of red blood cells, white blood cells, hemoglobin, hematocrit, mean corpuscular volume, mean corpuscular hemoglobin, and mean corpuscular hemoglobin concentration. All determinations were compared across treatment groups by one-way ANOVA.

\subsubsection{Physical Parameters}

The size, polydispersity index (PDI), and zeta potential (ל) of nanoparticle-based preparations of ML111 were characterized by Dynamic Light Scattering (DLS; Malvern ZetaSizer Nanoseries, Malvern, UK), according to manufacturer's instructions. Values represent mean of triplicate measurements of each parameter. The morphology of ML111NP nanoparticles was evaluated with cryogenic transmission electron microscopy (cryoTEM) using a 400-mesh copper grid. Images were recorded with a K2 Summit camera (Gatan Inc., Pleasanton, CA, USA) in counting mode on a Talos Arctica microscope (Thermo Fisher Scientific, Waltham, MA, USA) that was operated at $200 \mathrm{kV}$. Cryo-TEM images were collected with a defocus range of $2-4 \mu \mathrm{m}$.

The amount of ML111 loaded in mPEG-PCL-based nanoparticles was quantified by reverse-phase liquid chromatography by using a Shimadzu HPLC system configured with a Zorbax C18 column $(4.6 \times 75 \mathrm{~mm}, 3.5 \mu \mathrm{m}$ particle size, p/n 866953-902, Agilent (Santa Clara, CA, USA) after developing a standard curve with known amounts of ML111. Unknown samples were eluted from the $\mathrm{C} 18$ column at a flow rate at $0.3 \mathrm{~mL} / \mathrm{min}$ by using an isocratic method with a mobile phase consisting of $60 \%(v / v)$ acetonitrile in water containing $0.1 \%$ TFA. ML111 was detected at $228 \mathrm{~nm}$ with a retention time of $6.94 \mathrm{~min}$. Encapsulation efficacy was calculated as the amount of ML111 loaded in nanoparticle as 
a ratio of the initial amount of ML111 in the encapsulation procedure, and the loading capacity was calculated as the percentage of ML111 in nanoparticles in relation to the total mass of nanoparticles.

\subsubsection{In Vitro ML111 Release}

In vitro ML111 release was assessed using a modified equilibrium dialysis method [21]. Freshly prepared ML111-NP ( $2.5 \mathrm{~mL}$ of $2 \mathrm{mg} / \mathrm{mL}$ solution of ML111) was placed in a SlideA-Lyzer G2 dialysis cassette (20,000 MWCO, Thermo Fisher Scientific, Waltham, MA, USA) and dialyzed against the phosphate buffer saline containing $0.1 \%$ Tween 20 (PBST) at pH 7.4 and $37^{\circ} \mathrm{C}$. Samples $(50 \mu \mathrm{L})$ were withdrawn at pre-determined times $(0-144 \mathrm{~h})$ and replaced with a $50 \mu \mathrm{L}$ volume of a fresh buffer. Samples were quantified as described above. The release of ML111 from nanoparticles was fit to the following equation:

$$
\frac{M_{t}}{M_{\infty}}=M_{\max }-A_{1} e^{\left(\frac{t}{-\tau 1}\right)}-A_{2} e^{\left(\frac{t}{-\tau 2}\right)}
$$

where $M_{t}$ is the cumulative release of ML111 at time $t ; M_{\infty}$ is the cumulative release of ML111 at infinite time; $A_{1}$ and $A_{2}$ are the relative amounts of ML111 release associated with $\tau 1$ and $\tau 2$, the mean lifetimes of the fast-release and slow-release phases, respectively; and $M_{\max }$ is the total amount of ML111 release from both phases. The parameters were estimated by nonlinear least squares procedures using Marquardt's algorithm [22] and are reported $\pm 95 \%$ confidence interval.

\subsubsection{Cellular Toxicity Assay of ML111-NP}

The cellular toxicity of empty-NP (mPEG-PCL) and ML111-NP was assessed in SK-NMC and HEK239 cells using the Calcein AM cell viability assay (Corning, Glendale, AZ, USA). The cells were seeded in 96-well flat bottom plates at a density of $1 \times 10^{4}$ cells per well. The cells were treated with empty-NP (mPEG-PCL; 0.39-400 $\mu \mathrm{g} / \mathrm{mL}$ ) and ML111-NP formulation (0.95-500 nM) for $48 \mathrm{~h}$. The cells were then incubated with $10 \mu \mathrm{M}$ Calcein AM in DPBS buffer, as previously described [23].

\subsubsection{Cellular Internalization of ML111-NP}

Cells numbering $2.5 \times 10^{5}$ SK-N-MC cells/well were plated in 6-well plates and permitted to attach overnight prior to incubation with ML111-NP co-encapsulated with a SiNc dye $(20 \mu \mathrm{g} / \mathrm{mL})$ for $24 \mathrm{~h}$. Cells were co-stained with DAPI (NucBlue Live Cell Stain, Thermo Fisher Scientific, Waltham, MA, USA) and imaged using a Keyence BZ-X fluorescence microscope equipped with a Cy7 filter cube for SiNc (excitation, $710 \mathrm{~nm}$; emission $775 \mathrm{~nm}$ ) and DAPI (excitation, $360 \mathrm{~nm}$; emission, $460 \mathrm{~nm}$ ).

\subsection{In Vivo Efficacy of ML111-Based Nanoparticles (ML111-NP)}

A mouse xenograft model of Ewing's sarcoma was created using athymic nu/nu mice (4-6 weeks old; Charles River Laboratories, Wilmington, MA, USA). Mice were injected subcutaneously into the right flank with $2.5 \times 10^{6}$ SK-N-MC cells in $100 \mu \mathrm{L}$ of MEM medium prepared in Matrigel matrix (1:1 ratio, Corning Life Science). When tumors reached a size of $40-60 \mathrm{~mm}^{3}$, mice were randomly separated into four groups (five mice/group), as described above. Two doses of ML111-NP were tested, 4.5 and $15 \mathrm{mg} / \mathrm{kg}$. Tumor diameter measurements were made by using a caliper every other day for 28 days. Tumor volume was calculated by $\left(\right.$ width $^{2} \times$ length $) \times 0.5$.

\subsection{Statistical Analysis}

Statistical significance was calculated using a Student's $t$-test and paired control and test samples were analyzed with Prism 6.0 software (GraphPad Software, San Diego, CA, USA). 


\section{Results}

\subsection{Discovery of Lead Compound Using High-Throughput Functional Screening}

In order to identify new agents that inhibit the viability of Ewing's sarcoma cells, we conducted a phenotypic, high-throughput screen (HTS) using SK-ES-1 cells, a well characterized Ewing's sarcoma cell line harboring a type II EWS-FLI1 oncofusion protein $[24,25]$ and a chemical library composed of small molecules from the ChemBridge DIVERSet-CL and CORE Libraries (https:/ / www.chembridge.com/screening_libraries (accessed July 2016)). SK-ES-1 cells were treated individually with 10,500 compounds in the primary screen, each at a single concentration of $10 \mu \mathrm{M}$ for $48 \mathrm{~h}$, and cellular viability was assessed using Cell-Titer Glo (Figure 1A). Cells were treated with bortezomib and vehicle $(0.1 \%$ DMSO) as positive and negative controls, respectively. Positive hits were defined as compounds that inhibited SK-ES- 1 cell viability by at least $85 \%$. A total of 52 compounds were selected for subsequent dose-response studies. The activity of 27 of these compounds was confirmed, but the majority exhibited low potency $\left(\mathrm{IC}_{50}>1 \mu \mathrm{M}\right.$; Figure $\left.1 \mathrm{~B}\right)$. However, five compounds segregated from the rest, and among these five compounds, Compound 35 (Figure 1B) was selected for further analysis because of its relative drug-like structure, according to Lipinski's rules [26] and ease of synthesis. In silico screening of an additional $\sim 240,000$ library compounds identified 16 new compounds that exhibited greater than $80 \%$ structural similarity to Compound 35 (Scheme 1). Among the latter analogs, a compound now named ML111 exhibited 20-fold higher potency compared to Compound 35 and, thus, was selected for further studies (Figure 1C).

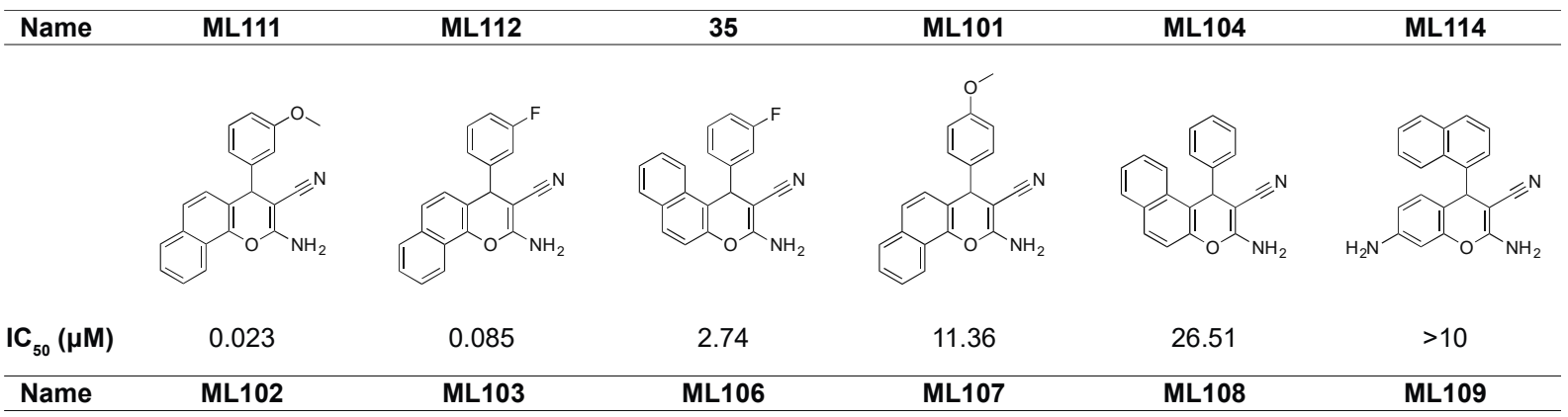

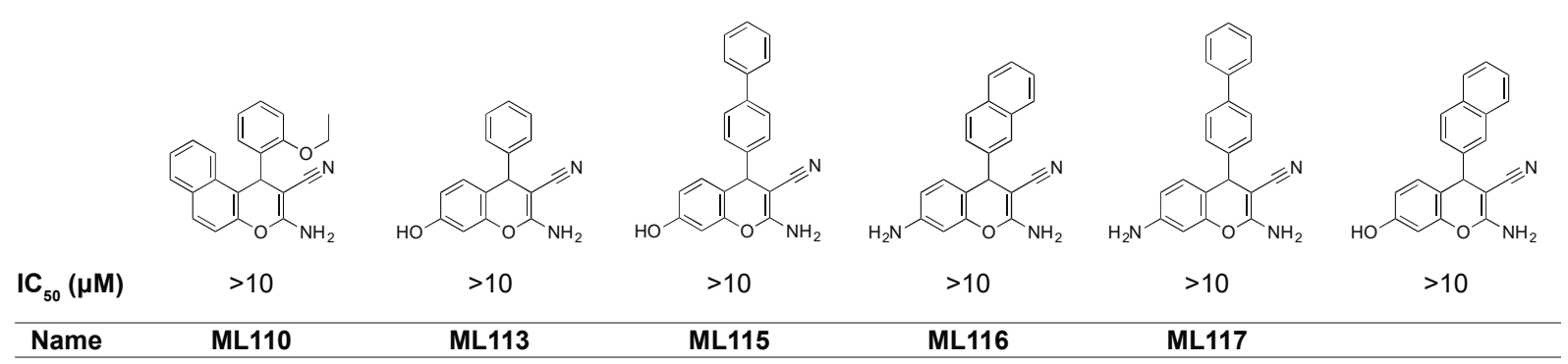
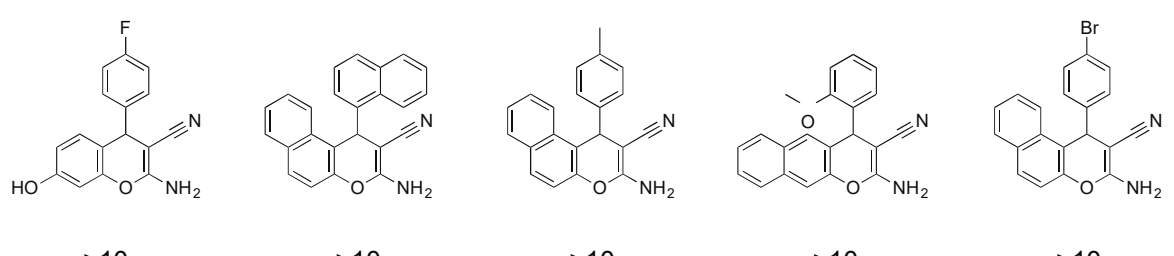

$\mathrm{IC}_{50}(\mu \mathrm{M})$

$>10$

$>10$

$>10$

$>10$

Scheme 1. Potency of ML111 analogs. Scheme shows the structures and SK-ES-1 cell growth inhibitory activity as dose-response $\mathrm{IC}_{50}$ values. 


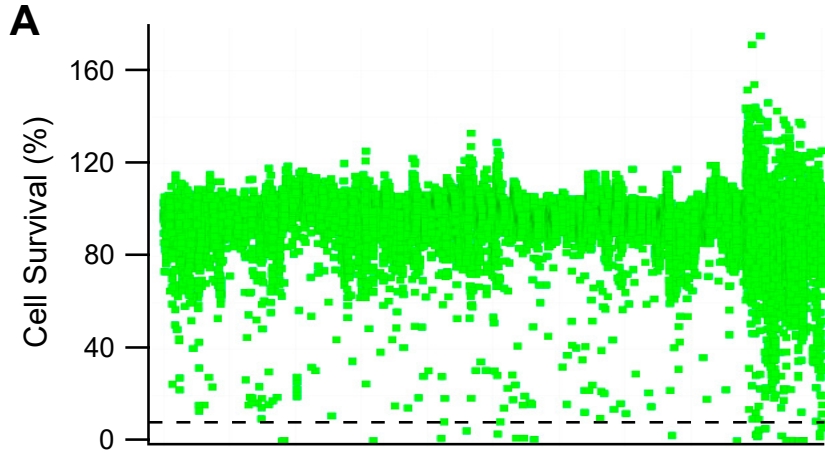

Compounds

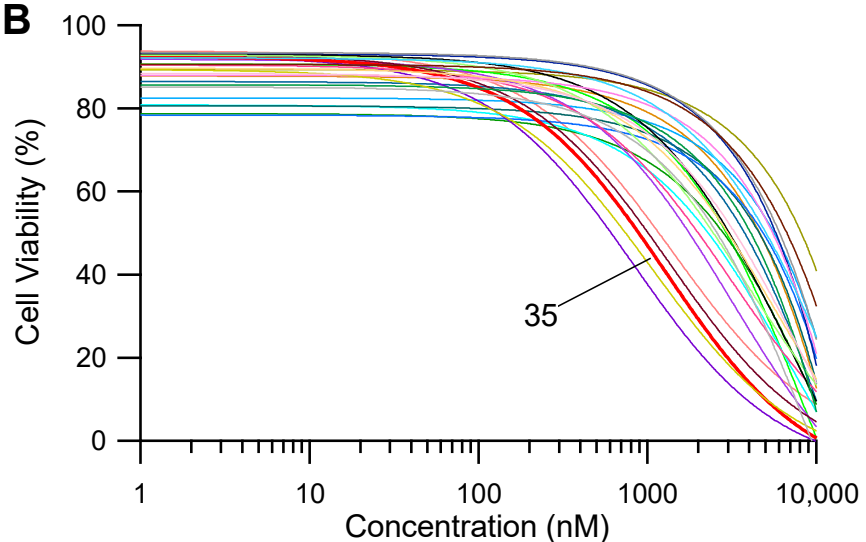

C

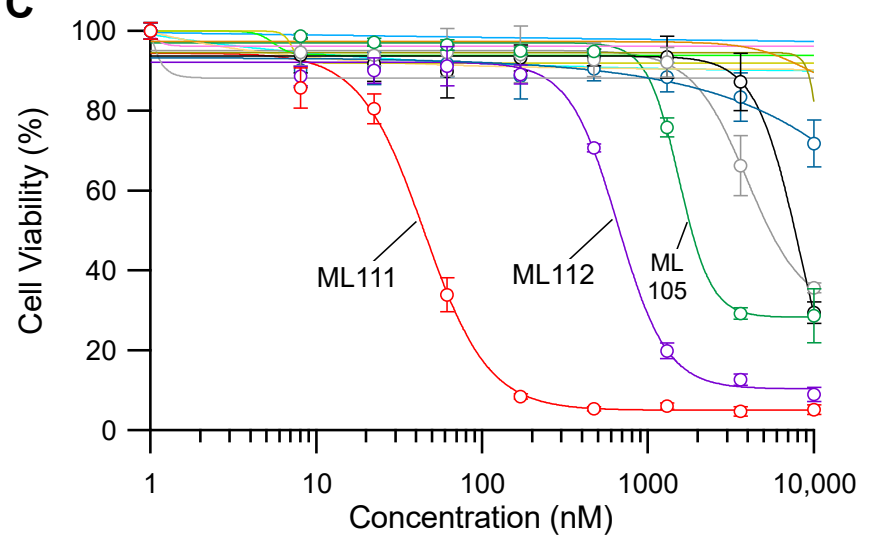

D

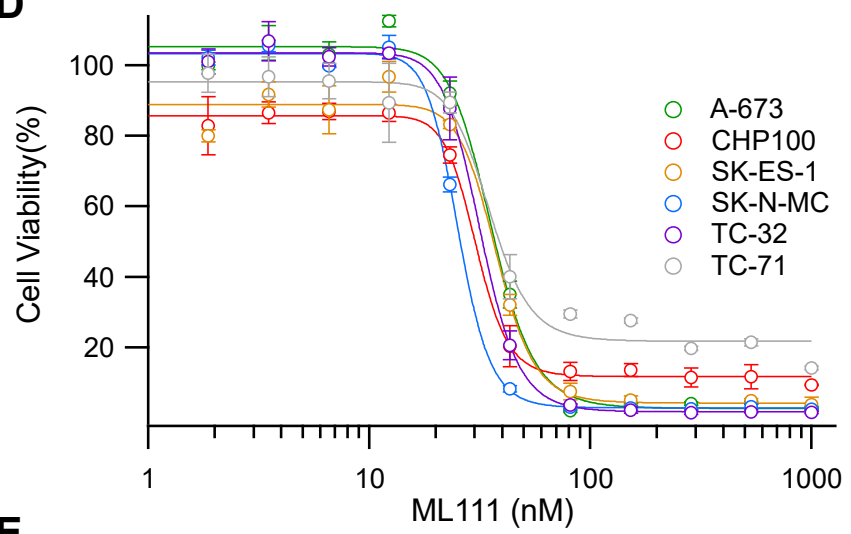

E

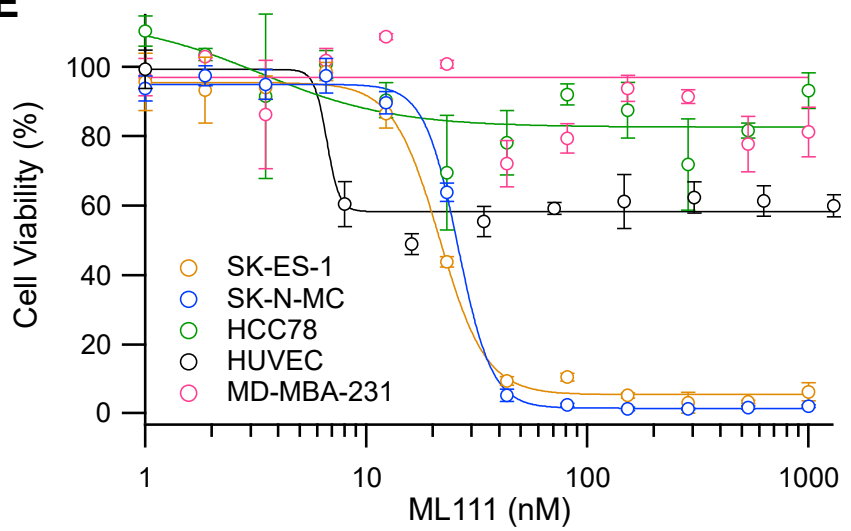

F

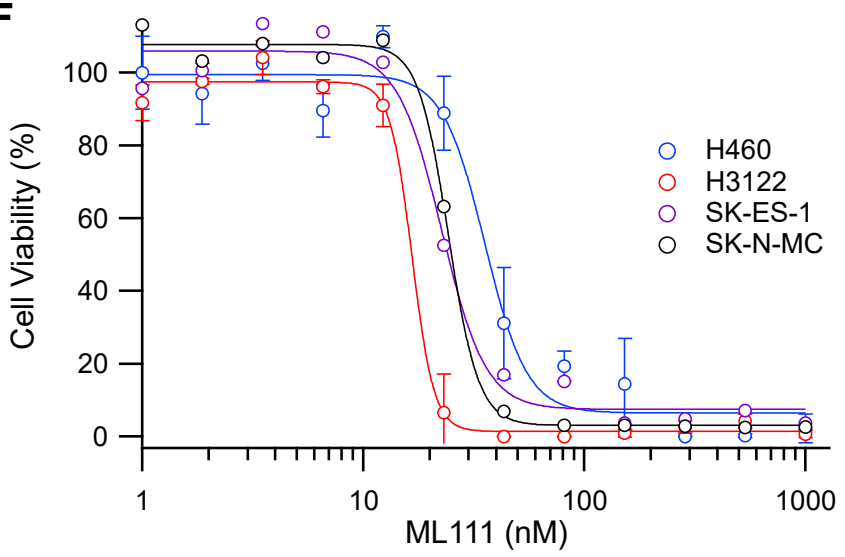

Figure 1. Lead compound selection process and the results of each step. (A) Primary screen: A scatter plot of the percentage cell survival of SK-ES-1 treated with 10,500 pure compounds at $10 \mu \mathrm{M}$ for $48 \mathrm{~h}$. Each dot represents one compound. Fifty-two hits $(0.5 \%$ of the screened chemicals) were selected for further studies based on their ability to reduce cell viability by $85 \%$ (the dashed line shows the cutoff for selection of hits). (B) Secondary screen: Confirming the activity of the identified hits from the primary screen. The dose-response curve studies confirmed the activity of twenty-seven (51.9\%) compounds. Compound 35 was selected for the tertiary screen. (C) Tertiary screen: The dose-response analysis of compound 35 and its structural analogs. ML111 was selected as the lead compound for further studies. (D) Dose-response analysis of Ewing's sarcoma cell lines with either type I or type II fusion protein after ML111 treatment. (E,F) Effect of ML111 on various cancerous and primary cell lines. Data in $(\mathbf{C}-\mathbf{F})$ shown as mean $\pm \mathrm{SD}(n=3)$. 


\subsection{ML111 Inhibits Viability of Ewing's Sarcoma Cell Lines Harboring Both Type I and II Fusion Proteins}

The inhibitory effect of ML111 was tested against an expanded panel of established Ewing's sarcoma cells harboring both type I and II EWS-FLI1 fusion proteins. All tested Ewing's sarcoma cell lines exhibited comparable sensitivity to ML111 (Figure 1D and Table S1), indicating that the effect of ML111 on Ewing's sarcoma viability was independent of the type of EWS-FLI1 fusion protein expressed.

We then performed cell viability studies on a panel of non-Ewing's sarcoma cancer cell lines to assess selectivity and determine if the inhibitory effect of ML111 is generalizable to cancers representing diverse histologies. ML111 inhibited growth of the ovarian cancer cell line ES-2 and lung cancer cell line H460 with potencies similar to that of the Ewing's sarcoma cell lines (Figure 1E and Table S1). However, the breast cancer cell line MDAMB-231, non-small cell lung carcinoma (NSCLC) cell line HCC78, and ovarian cell line SK-OV-3 were largely resistant to ML111 (Figure 1E and Table S1). An additional NSCLC line, H3122 (EML4-ALK), exhibited enhanced sensitivity to ML111 relative to Ewing's sarcoma cells. Non-cancerous human embryonic kidney cells 293 (HEK293) (Table S1) and primary human umbilical vein endothelial cells (HUVEC) were relatively insensitive to ML111 (Figure 1E). Overall, these data suggest that ML111 is a promising anti-cancer agent for treatment of Ewing's sarcoma and possibly specific molecular subset(s) of cancers.

\subsection{Single Enantiomer of ML111 Responsible for Anti-Viability Effect in Ewing's Sarcoma Cells}

ML111 harbors one chiral center (Figure 2A,B) and racemic ML111 was resolved into its individual enantiomers by chiral HPLC in order to determine the enantiospecificity of the compound. The analytical trace is consistent with the presence of two well-separated enantiomers with retention times of 13.3 and $16.5 \mathrm{~min}$ (Figure 2C). The specific rotation of individual enantiomers was determined by polarimetric analysis. Circular dichroism spectroscopic analyses of the isolated enantiomers demonstrated the expected mirror image spectra, while the racemate had zero net rotation of polarized light, indicating a mixture of two isomers in equal proportions (Figure 2D). The relative anti-viability potencies of $(R S)-M L 111,(S)-M L 111$, and (R)-ML111 were determined using SK-N-MC cells in vitro. (R)-ML111 was found to be the active enantiomer with an $\mathrm{IC}_{50}$ of $16.5 \pm 1.3 \mathrm{nM}\left(\mathrm{IC}_{50}\right.$ of racemic ML111 was $19.8 \pm 3.2 \mathrm{nM}$, Figure 2E). (S)-ML111 was devoid of activity in these studies (Figure 2E). These results demonstrate enantiomeric-specific activity of ML111.

\subsection{ML111 Induces Caspase-3/7-Dependent Apoptosis}

We performed live-cell imaging to determine if the loss of cell viability observed in ML111-treated Ewing's sarcoma cells is due to cytostatic or cytotoxic/apoptotic mechanisms. For these experiments, SK-ES-1 cells were treated with ML111 followed by the addition of CellEvent ${ }^{\mathrm{TM}}$ Caspase-3/7 detection reagent and imaged using the Incucyte Live Cell Analysis System. An increase in caspase 3/7-activated green fluorescent cells (outlined in blue line) is observed as early as $6 \mathrm{~h}$ after ML111 treatment (Figure 3A). To assess the specificity of ML111 (50 nM) in caspase activation and to ensure that the cells are not generically hypersensitive to perturbation of other signaling pathways, we tested cabozantinib (250 nM), a tyrosine kinase inhibitor (TKI) with multiple targets. Quantification of green fluorescent cells over the course of imaging shows 5-fold greater activation of caspase 3/7 in ML111-treated cells $(946.8 \pm 20.3)$ at $24 \mathrm{~h}$, as compared to vehicle $(189.4 \pm 12.1)$ or cabozantinib treated cells $(207.4 \pm 11.1)$ (Figure 3B). Caspase $3 / 7$ activation after ML111 treatment is reproducible in CHP100, A673, and TC-32 Ewing's sarcoma cell lines (Figure S1); dasatinib, another multikinase inhibitor with a broad-spectrum kinase-inhibition profile, was used in the latter studies to ascertain selectivity of ML111 in inducing apoptosis. 
<smiles>COc1cccc([C@H]2C(C#N)=C(N)Oc3c2ccc2ccccc32)c1</smiles>

(R)-ML111 $[\alpha]_{D}^{24}=-180^{\circ}$

D

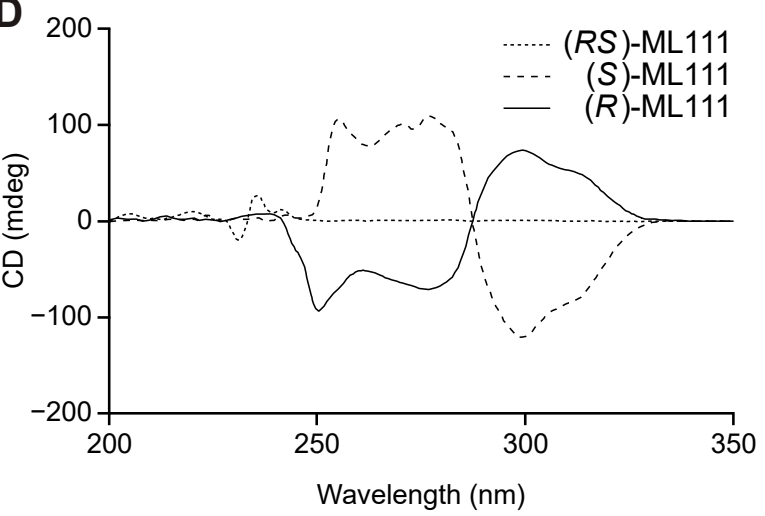

B<smiles>COc1cccc([C@H]2C(C#N)=C(N)Oc3c2ccc2ccccc32)c1</smiles>

(S)-ML111

$[\alpha]_{D}^{24}=+180^{\circ}$

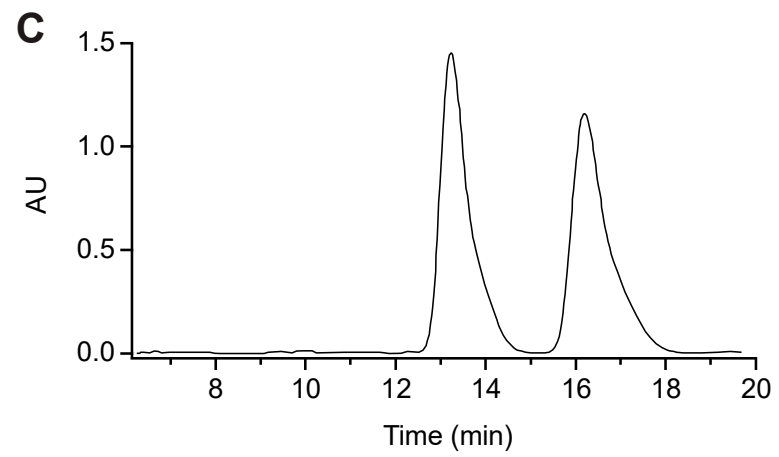

E

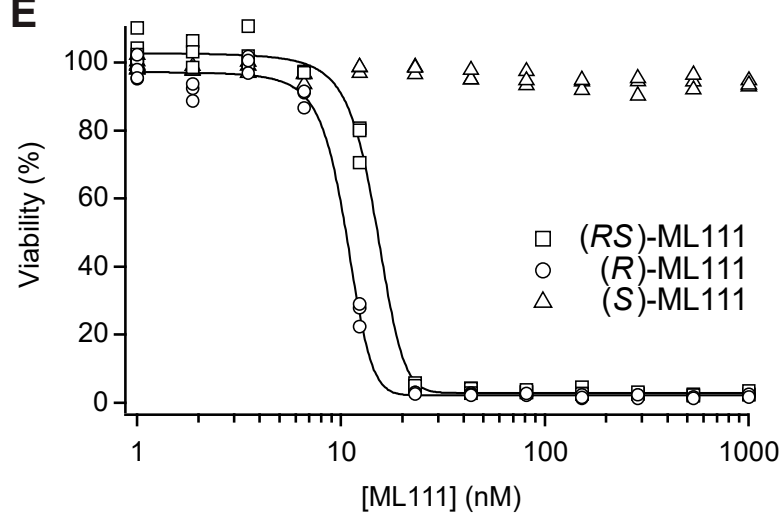

Figure 2. Enantiospecificity of ML111 action in Ewing's sarcoma cells. (A,B) (R)-ML111 and (S)-ML111 chemical structures. (C) The racemate ML111 was resolved into its individual enantiomers by chiral chromatography. HPLC analysis of racemate clearly identified two single enantiomer peaks. AU: absorbance units. (D) CD spectra of (R)-ML111, (S)-ML111, and racemate ML111. The first enantiomer to elute from the column in (C) shows a specific rotation value of $-180^{\circ}$, while that for the second enantiomer is $+180^{\circ}$. (E) Dose-response analysis of racemate ML111, (S)-ML111, and (R)-ML111 in SK-N-MC cells with various concentrations of each compound ranging from 0.001 to $1 \mu \mathrm{M}$ for $48 \mathrm{~h}$.

Caspases, a family of cysteine endoproteases, play a central role in all known pathways of apoptosis [27]. We examined caspase 3/7 cleavage by immunoblot analyses to validate enhanced caspase 3/7 activity observed in live-cell studies (Figure 3A). These data reveal a time-dependent increase in cleaved caspase 3/7, albeit at the earlier hours (6 and $12 \mathrm{~h}$ ); the levels are at or below the threshold of antibody detection since the events are occurring in a smaller cell populations. (Figure 3C). We confirmed these results using a second apoptosis marker, poly ADP-ribose polymerase (PARP) $[28,29]$. PARP cleavage also increases in a time-dependent manner in cells treated with ML111. (Figure 3D). Immunoblotting results showing increase in cleaved caspase 3/7 and cleaved PARP in ML111 treated cells are consistent with live-cell imaging studies (Figure 3A).

Next, we examined the localization of annexin V on the surface of SK-N-MC cells treated with ML111 by staining with an anti-annexin V antibody and flow cytometry. Untreated SK-N-MC cells exhibited very low levels of annexin V staining on the cell surface (Figure 3E, time 0). SK-N-MC cells treated with ML111 for at least $12 \mathrm{~h}$ exhibited robust Annexin V staining on the cell surface, indicating initiation of the apoptosis program. Similarly, co-staining these cells with propidium iodide (PI), a marker of cell death, shows that, after $24 \mathrm{~h}$ of ML111 treatment, a large number of cells are terminally apoptotic (Figure 3E).

Live-cell imaging studies indicated rapid and robust activation of caspase 3 and/or caspase 7 in SK-ES-1 and SK-N-MC cells treated with ML111, and all supporting data were consistent with a role for caspases in ML111-induced loss of viability (Figure 3B-D). Consistently, we found that the cell-permeant, irreversible pan-caspase inhibitor Z-VADFMK (Z-VAD) partially rescued cell viability of SK-N-MC treated with ML111 (Figure 3F), 
providing direct evidence for the role of caspase activation in the mechanism of ML111 action. Taken together, the above results conclusively demonstrate that ML111 induces apoptotic cell death in these Ewing's sarcoma model cell lines.

A

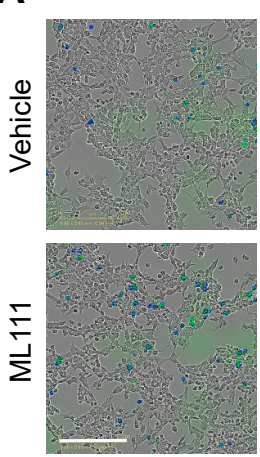

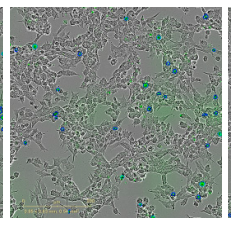

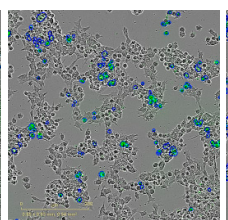

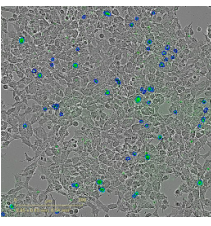

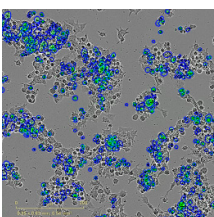

12
C

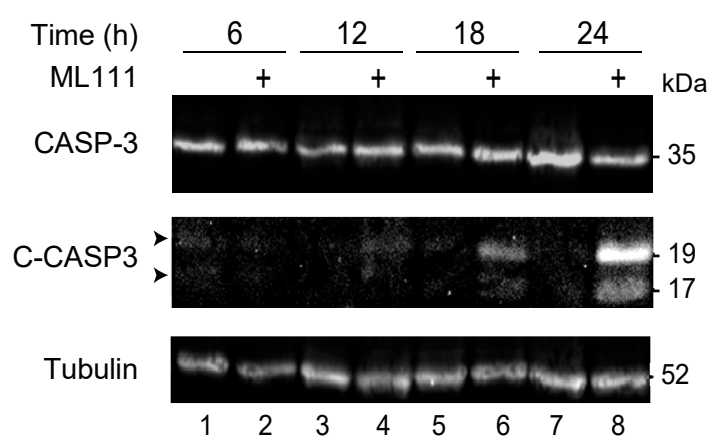

E

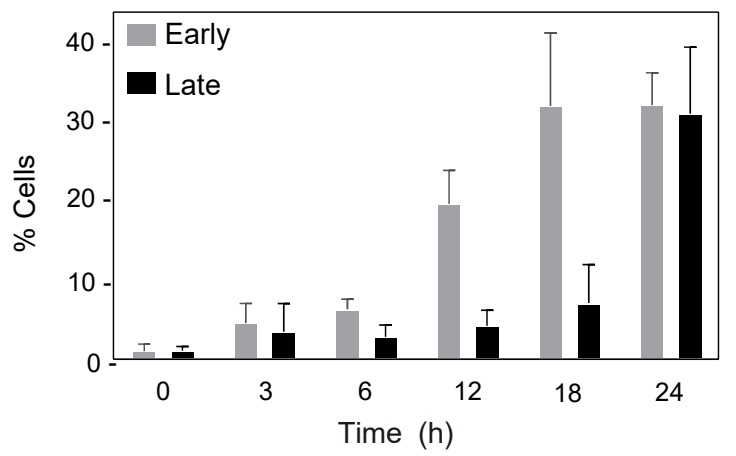

B

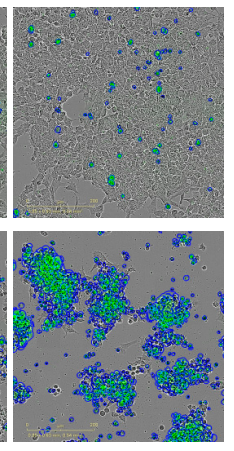

24

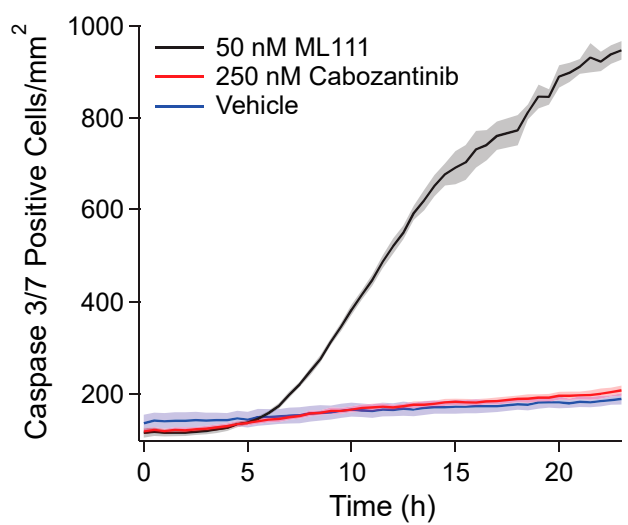

D

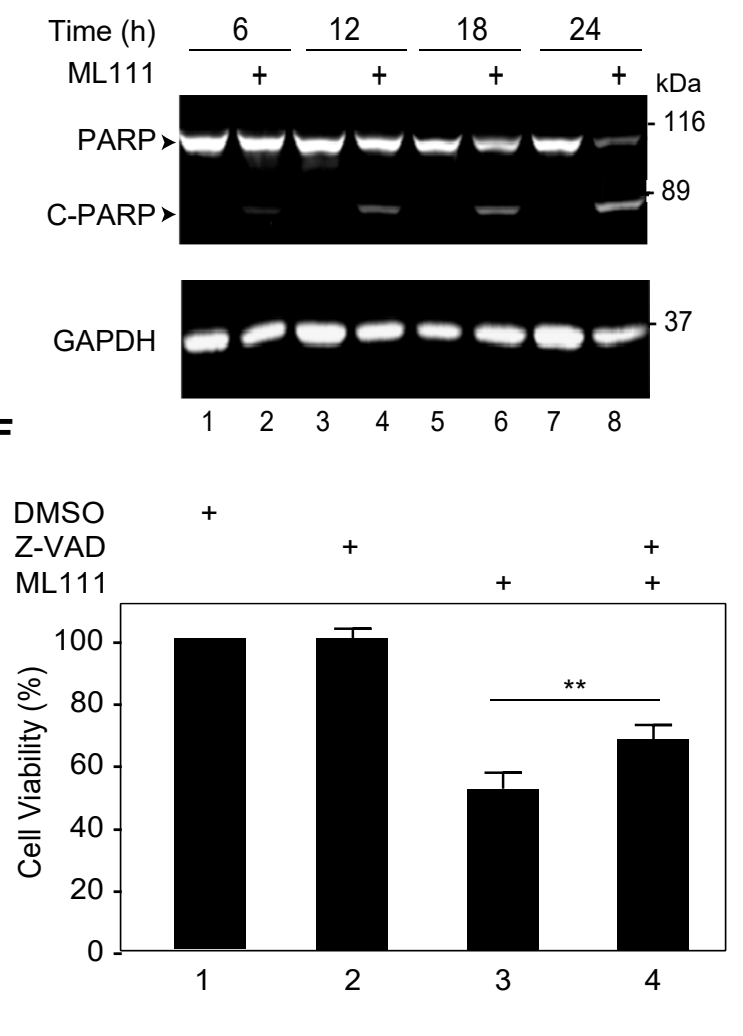

Figure 3. Induction of caspase-dependent apoptosis by ML111 in a time-dependent manner. (A) Induction of caspase $3 / 7$ activity after vehicle, ML111 (50 nM), or cabozantinib $(250 \mathrm{nM})$ treatment at indicated time intervals. Green nuclear fluorescence indicates cellular caspase 3/7 activation as detected by using CellEvent Caspase-3/7 Green Detection Reagent. (B) Quantification of caspase-3/7 activated cells at indicated times. The mean is shown, and the shaded regions represent the SEM $(n=4)$. (C) Immunoblot analysis of pro-caspase 3 cleavage forming active caspase 3 after $12 \mathrm{~h}$ of treatment with ML111. (D) Western blot analysis of PARP cleavage as a marker of caspase 3 activation and apoptosis. (E) Measurement of early and late apoptosis in ML111 treated cells as measured by annexin V and propidium iodide staining and flow cytometry. (F) Caspase inhibitor Z-VAD attenuates ML111-mediated induction of apoptosis. Asterisks (**) indicate statistically significant rescue of ML111 induced apoptosis by Z-VAD treatment $(p<0.01)$. GAPDH and $\alpha$-tubulin were used as loading controls. CASP-3: Caspase 3; C-CASP3: Cleaved Caspase 3; C-PARP: Cleaved PARP. Scale bar in panel A= $200 \mu \mathrm{m}$. 


\subsection{ML111 Induces Prometaphase Arrest in SK-N-MC Cells Independent of an Effect on Microtubule Dynamics}

The effect of ML111 on cell cycle dynamics was assessed in SK-N-MC cells to determine if ML111-induced cell death was associated with altered control of cell cycle. Treatment of asynchronous SK-N-MC cells with ML111 resulted in the accumulation of cells in the G2/M phase in a time-dependent manner (from $27 \%$ at $2 \mathrm{~h}$ to $51 \%$ at $12 \mathrm{~h}$; Figure $4 \mathrm{~A}$, bottom panels), indicating the induction of cell cycle arrest at or near the G2/M checkpoint. We next analyzed the expression of three M-phase specific markers to confirm arrest in M phase: cyclin B1, phospho-Ser10-histone $\mathrm{H} 3\left(\mathrm{p}-\mathrm{H} 3^{\mathrm{Ser} 10}\right)$, and the cell division cycle 20 protein (CDC20). Degradation of cyclin B1 and CDC20 is required for cell cycle progression through the G2/M checkpoint [30]. Histone H3 is phosphorylated at Ser10 in late G2/M in association with mitotic chromatin condensation [31-33]. Treatment of SK-N-MC cells with ML111 resulted in the time-dependent accumulation of all three markers (Figure 4B), suggesting that ML111-induced M phase arrest.

Cell cycle arrest during $\mathrm{M}$ phase can be a result of disruption of microtubule polymerization. The effect of ML111 on microtubule polymerization was evaluated by using purified components in a cell-free assay. Unlike known microtubule regulators paclitaxel and colchicine, which strongly stimulated and inhibited microtubule polymerization, respectively, ML111 neither promoted nor inhibited microtubule polymerization (Figure 4C), suggesting that the induction of M phase arrest by ML111 is independent of its ability to affect microtubule polymerization directly.

We conducted immunocytochemical staining to define the point of ML111-induced arrest in SK-N-MC cells with more precision. Immunocytochemical staining with anti$\mathrm{p}-\mathrm{H} 3^{\mathrm{Ser} 10}$, a marker of mitotic condensed chromatids, and counterstaining with DAPI revealed that asynchronous SK-N-MC cells treated with ML111 exhibited condensed but unaligned chromosomes, as compared to vehicle-treated cells (Figure 4D, right panel). This finding suggests that ML111 arrested SK-N-MC cells at prometaphase [34].

\subsection{Quantitative Proteomic Analysis of ML111-Treated Ewing's Sarcoma Cells}

The effect of ML111 treatment on global cellular processes in SK-N-MC cells was assessed using an isobaric-tag peptide labeling approach to quantify changes in the whole cellular proteome. A total of 7471 non-redundant proteins were identified at a $1 \%$ FDR, of which 7122 were quantified across five treatment times, between 1.5 and $24 \mathrm{~h}$ (Table S2). Our analyses revealed that treatment of SK-N-MC cells with ML111 resulted in time-dependent stabilization of numerous cell cycle proteins, most of which are substrates for the anaphase-promoting complex/cyclosome (APC/C), an E3 ubiquitin ligase that targets mitotic factors for rapid proteasomal degradation (Figure 5A and Appendix A). APC/C activity drives cell cycle progression through mitosis and is the focus of the spindle assembly checkpoint (SAC), which blocks APC/C-mediated protein degradation and prevents premature chromosome separation (Figure 5B). ML111 treatment resulted in the accumulation of cyclin B1 and securin, which are normally degraded rapidly at the onset of mitotic exit, as well as the numerous other factors that are degraded in late mitosis and not required during interphase. However, not all substrates of APC/C were observed to accumulate in Ewing's sarcoma cells treated with ML111. Two factors including cyclin A2 [35] and HOXC10 [36], which circumvent MCC inhibition of APC/C-CDC20-mediated ubiquitination and are normally degraded during late prophase or early prometaphase, did not accumulate in cells treated with ML111. NEK2A is also a known prophase APC/C substrate [37], but this protein was not detected in these studies. While we have no direct evidence for ubiquitination of cyclin A2 or HOXC10, these data suggest that the APC/C complex may be enzymatically capable of carrying out the E3 ligase reaction-at least using these factors as a substrate - suggesting that ML111 may not function as a direct or global inhibitor of APC/C in SK-N-MC cells. 
A
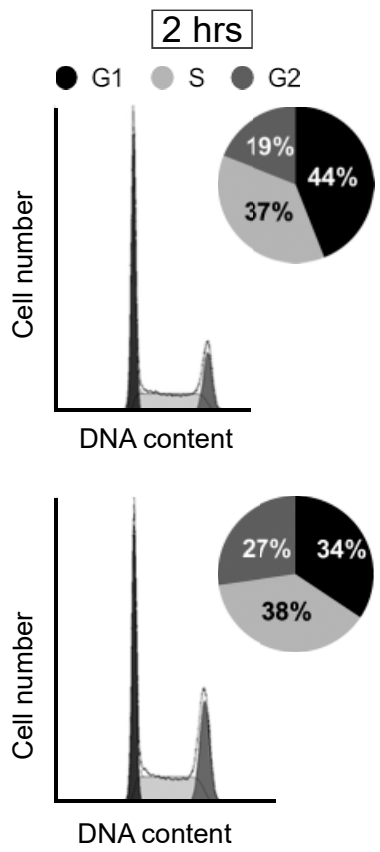

B

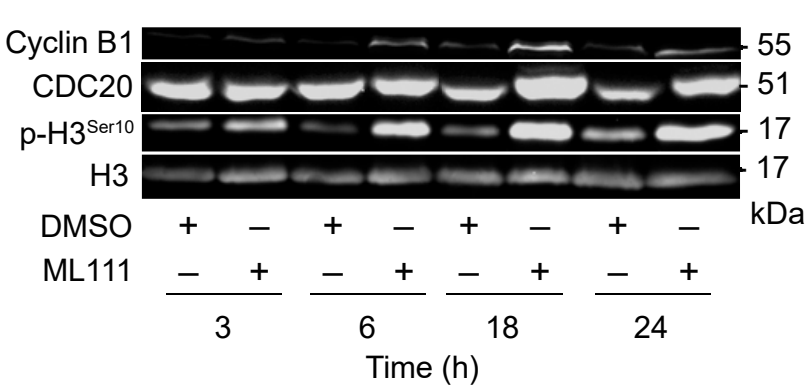

$4 \mathrm{hrs}$
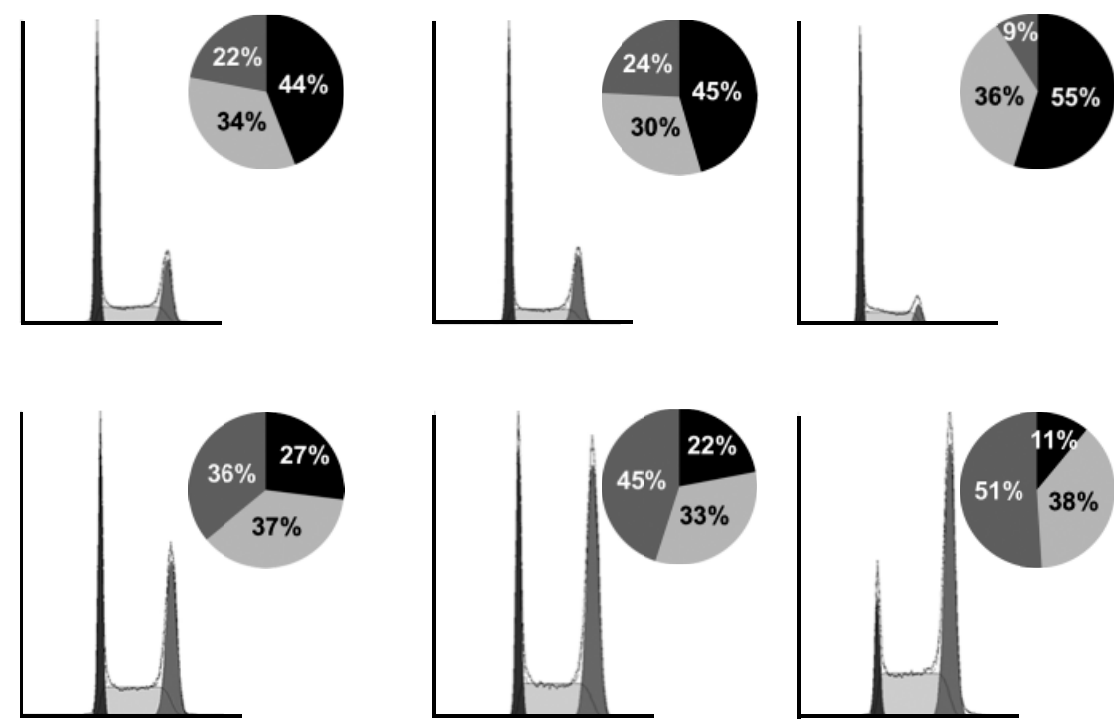

D

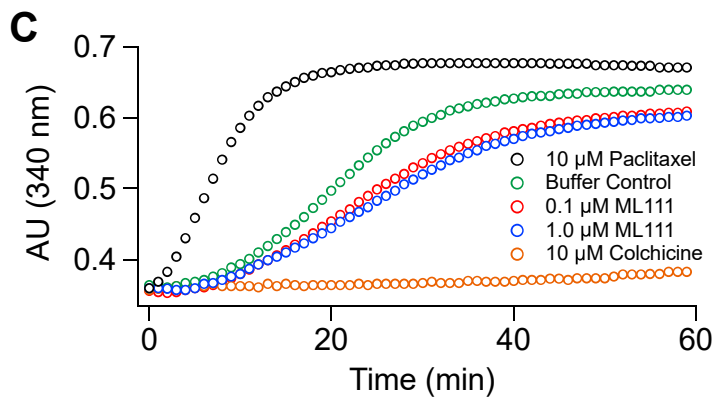

\section{$\alpha$-Tubulin $\bullet$ DAPI $\circ \mathrm{p}-\mathrm{H} 3^{\text {Ser10 }}$}
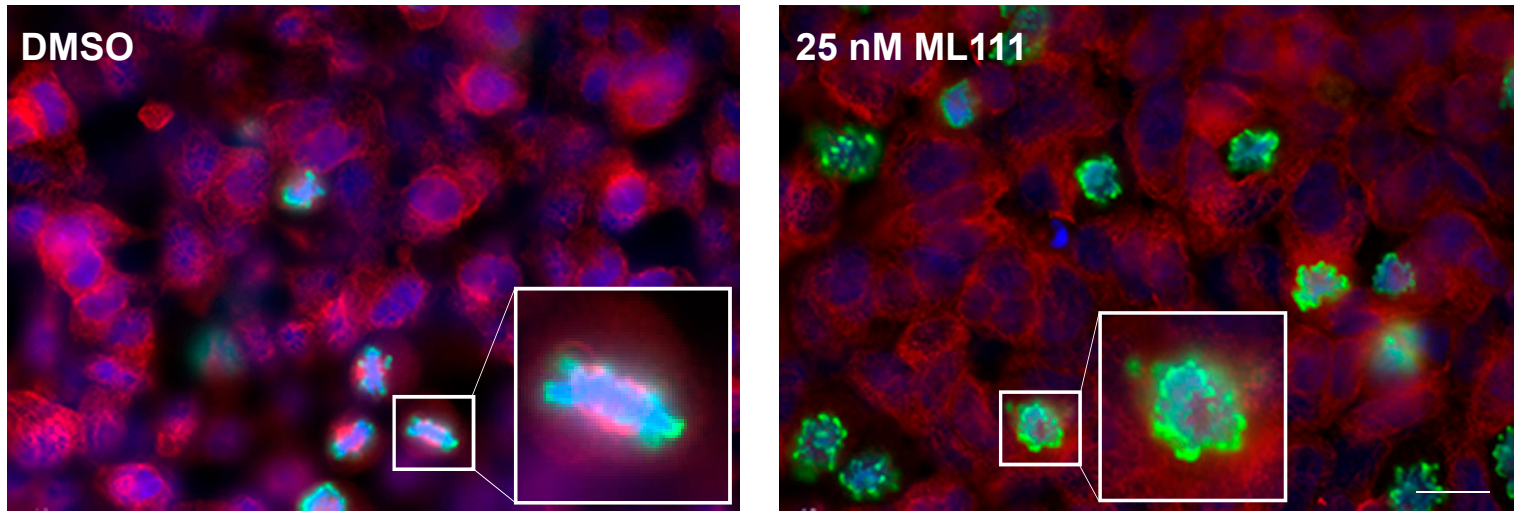

Figure 4. ML111 induced prometaphase arrest without altering microtubule dynamics. (A) Cell cycle analyses by flow cytometry in asynchronous SK-N-MC cells treated with 0.1\% DMSO (upper panel) or 100 nM ML111 (lower panel). (B) Immunoblot analysis for cyclin B1, p-H3 ${ }^{\mathrm{Ser} 10}$, and CDC20 in lysates from asynchronized SK-N-MC cells treated with $100 \mathrm{nM}$ ML111 or $0.1 \%$ DMSO. Total histone H3 (H3) antibody was used as a control. (C) Cell-free tubulin polymerization assay. ML111 neither stimulated nor inhibited tubulin polymerization in vitro. Paclitaxel and colchicine were used as tubulin polymerization inducer and inhibitor agents, respectively. General tubulin buffer (Cytoskeleton, Inc.) was used as a control. AU: absorbance units. (D) ML111 induced prometaphase arrest. Asynchronized SK-N-MC cells were treated with either DMSO $(0.1 \%)$ or ML111 ( $25 \mathrm{nM})$ for $12 \mathrm{~h}$. The nuclei were stained with DAPI (blue), microtubules ( $\alpha$-tubulin, red), and mitotic chromosomes $\left(\mathrm{p}-\mathrm{H} 3^{\mathrm{Ser} 10}\right.$, green). One representative result was shown from three independent experiments. Magnification: $63 \times$. Scale bar $=10 \mu \mathrm{m}$. 
A

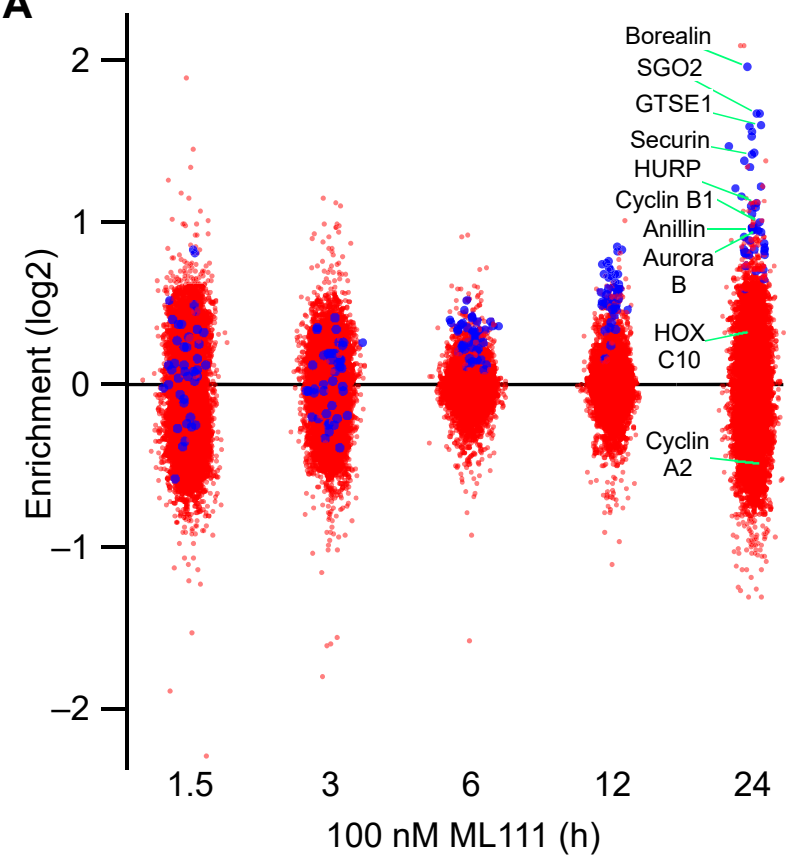

B

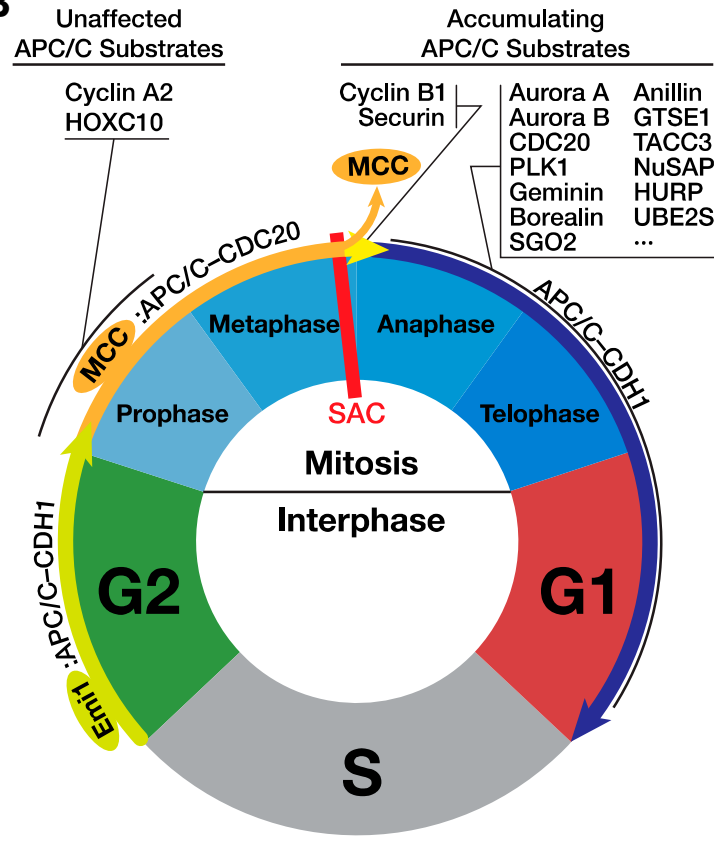

Figure 5. ML111-induced accumulation of APC/C substrates in SK-N-MC cells. (A) Scatter plot showing relative quantitative enrichment of 7122 proteins by mass spectrometry in response to ML111 relative to vehicle control in SK-N-MC cells. Known cell cycle proteins upregulated $>1.5$-fold $(\log 2>0.58)$ are shown in blue. (B) Diagram showing where the accumulating APC/C substrates would normally be ubiquitinated by the APC/C complex in the cell cycle. The diagram illustrates the dependence the cell cycle progression on APC/C co-activators CDC20 and CDH1, the spindle assembly checkpoint (SAC), mitotic checkpoint complex (MCC), and the location in the cell cycle where various substrates are expected to be ubiquitinated.

\subsection{Formulation of Nanoparticle-Based Drug Delivery System for ML111}

A nanoparticle-based drug delivery system was used for in vivo efficacy studies of ML111 to overcome the limited aqueous solubility of the compound. For this purpose, we used biocompatible methoxy polyethylene glycol-poly(caprolactone) block polymers (mPEG-PCL). The use of the biodegradable mPEG-PCL-based nanoparticles allowed us to achieve high ML111 loading capacity due to the lipophilic PCL core yet maintain high water-solubility owing to the presence of the hydrophilic PEG shell. Various concentrations of mPEG-PCL (20-80 mg/mL in acetone) were mixed with a fixed concentration of ML111 (2.25 mg/mL, also in acetone) to optimize drug loading and stability in physiological solution. Use of $80 \mathrm{mg} / \mathrm{mL}$ of $\mathrm{mPEG}-\mathrm{PCL}$ and $2.25 \mathrm{mg} / \mathrm{mL}$ of ML111 provided an encapsulation efficacy and loading capacity of $89.3 \%$ and $2.44 \%$, respectively (Table S3). Cryogenic transmission electron microscopy images revealed spherical morphology for ML111-NP, with an average size of $21.1 \pm 0.2 \mathrm{~nm}$ (Figure 6A and Figure S2). ML111-NPs have a mean hydrodynamic diameter of $31.8 \pm 0.2 \mathrm{~nm}$ by dynamic light scattering (Figure S3 and Table S3) and a neutral zeta potential of $0.12 \pm 0.01$ (Table S3). The polydispersity index (PDI) of ML111-NP was less than 0.1 with a unimodal distribution (Table S3) [38]. These analyses demonstrated that the nanoparticle-based formulation of ML111 possesses the required size and a nearly neutral charge, both of which should result in extended blood levels, enhanced tumoral accumulation via passive targeting, minimal renal clearance, and impaired detection by macrophages [38]. The enhancement of solubility of ML111 in the $\mathrm{mPEG}$-PCL nanoparticle allowed us to achieve a therapeutically relevant dosage (4.5-15 mg/kg) for in vivo assessment. 

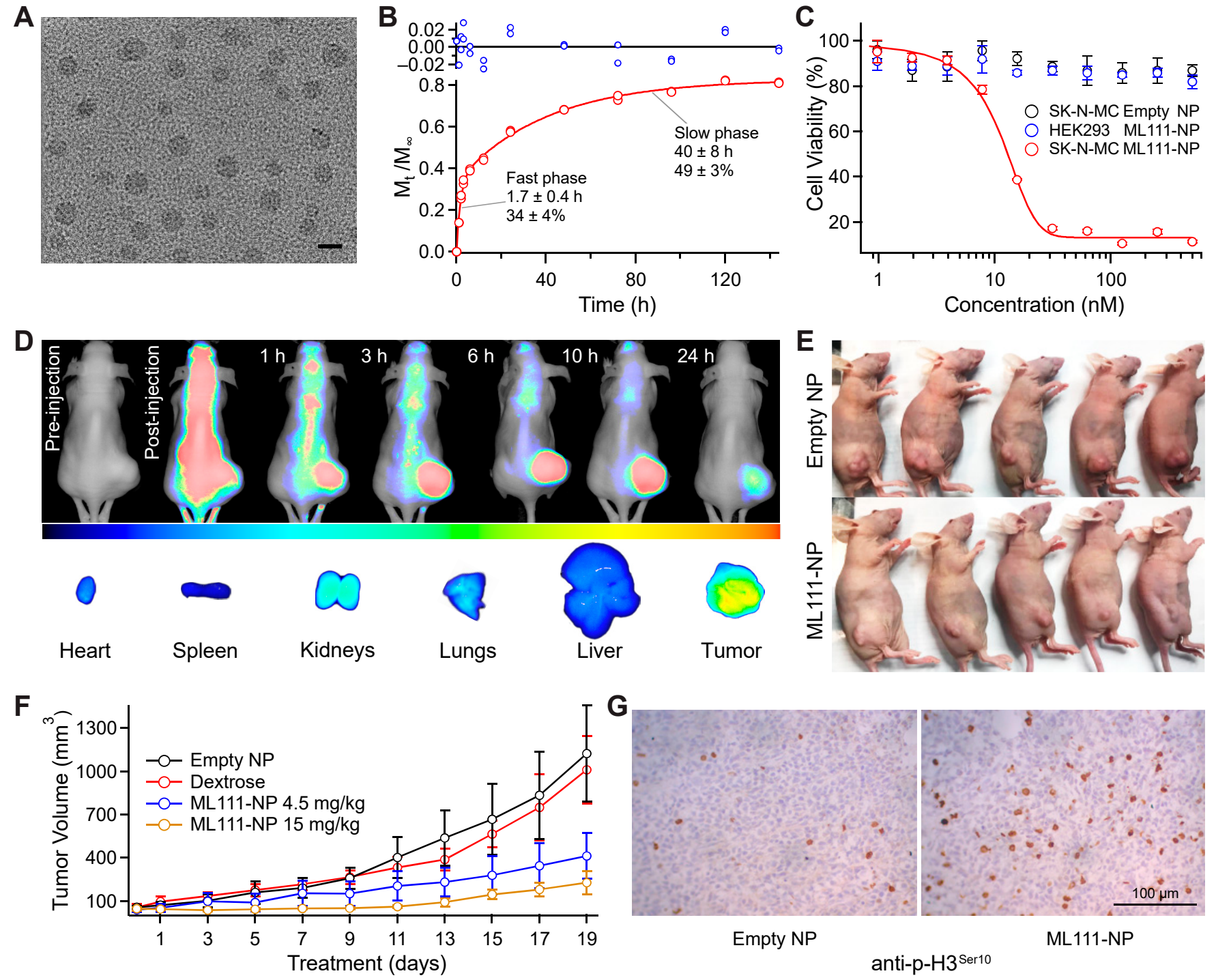

Figure 6. Characterization of ML111-NP. (A) Cryo-TEM image of ML111-NP. See Figure S2 for a full-resolution image. (B) ML111 released from nanoparticles in two phases in vitro. (C) Effect of empty NP and ML111-NP on viability of SK-N-MC and HEK293 cells after $48 \mathrm{~h}$ of incubation. (D) Fluorescence images of nude mice with subcutaneous SK-N-MC tumors pre-, post-, and at 1, 3, 6, 10, and $24 \mathrm{~h}$ after i.v. injection of ML111-NP (co-encapsulated with the NIR SiNc dye for fluorescence visualization) and fluorescence images of various organs and tumors at $24 \mathrm{~h}$ post-injection. Images were recorded on the Pearl Impulse Scheme $800 \mathrm{~nm}$ channel. (E) Representative mice bearing subcutaneous SK-N-MC xenografts and treated with empty nanoparticles or those containing ML111, as indicated. Mice are shown at necropsy. Reduction in xenograft tumor volume was observed in mice treated with ML111-NP. (F) A tumor growth profile after i.v. injections with ML111-NP, empty nanoparticles, or 5\% dextrose. Data are shown as mean \pm SD $(n=3)$. (G) Immunohistochemical staining with anti-p-H3 ${ }^{\text {Ser10 }}$ in SK-N-MC xenograft tissues from mice treated with empty nanoparticles or those loaded with ML111 $(15 \mathrm{mg}$ of ML111/kg). See Figure S6 for a quantification of the results. Scale bar $=20 \mathrm{~nm}$ in panel A and $100 \mu \mathrm{m}$ in panel G.

The in vitro release behavior of ML111-NP in the physiological buffer followed a typical biphasic pattern with a fast initial phase, during which $\sim 34 \%$ of the ML111 cargo was released with a mean lifetime of $1.7 \pm 0.4 \mathrm{~h}$ and a slow phase during which $\sim 49 \%$ of ML111 was released with a mean lifetime of $40 \pm 8 \mathrm{~h}$ (Figure 6B). The release of the remaining $\sim 17 \%$ of the ML111 was too slow to be quantified. Collectively, these findings suggest that the spontaneous leakage of ML111 from this nanoparticle formulation is unlikely, and the preparation appears to exhibit inherent sustained release properties [39,40]. 


\subsection{Effect of ML111-NP on Viability of SK-N-MC and HEK293 Cells}

ML111 was co-encapsulated with a near-infrared (NIR) dye, SiNc, to assess intracellular uptake of ML111 nanoparticle formulation. The fluorescence signal of SiNc indicated substantial internalization of ML111-NP within SK-N-MC cells (Figure S4). ML111-NP, but not empty nanoparticles, inhibited the viability of SK-N-MC cells in vitro with an $\mathrm{IC}_{50}$ of $10.8 \mathrm{nM}$ ML111 (Figure 6C). In contrast, ML111-NP did not inhibit the viability of HEK293 cells (Figure 6C), consistent with our earlier studies in non-Ewing's sarcoma cell lines (Figure 1C). These findings also indicate that mPEG-PCL formulation is nontoxic to non-malignant HEK293 cells.

\subsection{ML111 Decreases Tumor Growth in a Mouse Xenograft Model of Ewing's Sarcoma}

A mouse model was employed to evaluate the in vivo efficacy of ML111-NP. Nude mice bearing subcutaneous SK-N-MC xenografts in the flank were injected with ML111-NP containing the near-infrared dye SiNc. The NIR fluorescence signal of SiNc-loaded ML111$\mathrm{NP}$ was detected in the xenograft as early as $1 \mathrm{~h}$ after single injection and reached maximum intensity between 6 and $10 \mathrm{~h}$ after injection (Figure 6D). A strong NIR fluorescence signal was observed in the xenograft, as compared to other organs collected at $24 \mathrm{~h}$, which further confirmed accumulation and retention of ML111-NP within the xenograft (Figure 6D).

Mice bearing $\sim 40-60 \mathrm{~mm}^{3}$ tumors (Figure $6 \mathrm{E}$ ) were injected intravenously with ML111$\mathrm{NP}$ at two doses, 4.5 and $15 \mathrm{mg} / \mathrm{kg}$, every other day for 19 days. Two groups of control mice received equal volume injections of $5 \%$ dextrose or empty nanoparticles in $5 \%$ dextrose. A $67 \%$ and $85 \%$ reduction in tumor growth was observed in 4.5 and $15 \mathrm{mg} / \mathrm{kg}$ treatment groups, respectively, after 19 days (Figure 6F). Mice in both control groups were euthanized before 28 days due to the limitation of allowable tumor volume $\left(2000 \mathrm{~mm}^{3}\right)$, while ML111NP treated group survived until day 48 , at which point the mice were euthanized for further histological and toxicity studies.

Mice treated with ML111-NP did not exhibit loss of body weight (Figure S5), suggesting that ML111-NP was well tolerated and non-toxic over the course of these studies. Neither dose-limiting toxicity nor maximum tolerated dose could be determined due to the lack of toxicity of ML111-NP over the dosage range utilized in the present study.

Xenografts were sectioned and examined by immunohistochemistry for levels of $\mathrm{p}-\mathrm{H} 3^{\mathrm{Ser} 10}$, a marker of mitosis that was elevated in SK-N-MC cells treated with ML111 in vitro (see Figure 4B,D). Xenografts from ML111-NP-treated mice exhibited two-fold greater levels of $\mathrm{p}-\mathrm{H} 3^{\mathrm{Ser} 10}$ than those from control xenografts, consistent with a ML111induced block in prometaphase of the cell cycle in vivo (Figures 6C and S6).

Post-mortem analyses of treated and control mice also included the evaluation of ML111-induced toxicity to major organs by assessment of surrogate biomarkers and toxicity to the hematopoietic system by examination of circulating levels of various cellular components of blood and parameters of the circulatory system (Figure S7). None of these measurements were consistent with adverse effects of ML111 in vivo over the time-course of these studies.

\section{Discussion}

Ewing's sarcoma patients with metastatic or relapsed disease have poor outcomes despite intense and aggressive multimodal treatment strategies, including high-dose chemotherapy regiments. Despite the identification of pathognomonic fusions involving EWSR1 and FLI1 genes nearly thirty years ago, there is a dearth of approved molecularly targeted therapeutic agents in clinical use. Notably, EWS-FLI1 and related fusions are deemed essentially undruggable because of the absence of intrinsic enzyme activity and a high degree of predicted disorder in the protein structure [41]. Intensification of preclinical discovery efforts has resulted in the identification of novel agents (e.g., TKI-216, IMG-7289) that are currently being investigated in clinical trials; however, the efficacy and, importantly, the durability of these agents are still unknown. 
Therapeutic resistance is a nearly inevitable liability in the case of targeted therapeutics; thus, the development of multiple agents for use in the pharmacological arsenal is essential. Here, we undertook a high-throughput phenotypic screen to identify compounds with activity against Ewing's sarcoma. We utilized a forward pharmacological screen, coupled with in silico mining of a large chemical library in order to identify new agents capable of inhibiting Ewing's sarcoma cell viability. We postulated that a high-throughput phenotypic strategy would be advantageous in this case, given the challenges associated with identifying specific target proteins (for a reverse pharmacological approach) downstream of the complex, dysregulated transcriptional program driven by EWS-FLI1 or related fusion oncogenes. Furthermore, this target-agnostic approach has the potential to assist in the identification of previously unknown synthetic vulnerabilities that operate concomitantly or downstream of the fusion protein.

After identification of the lead compound, in silico mining resulted in the discovery of ML111. ML111 possesses nearly uniform potency again all six Ewing's sarcoma cell lines tested, but it is inactive in many other cancer cell lines, including lung and breast carcinoma, as well as non-neoplastic cells such as HUVEC (Table S1). However, it is intriguing that ML111 potently inhibited the EML4-ALK fusion-driven H3122 and KRAS/PI3KCAmutant H460 lung cancer cell lines. Since the oncogenic driver varies between the Ewing's sarcoma and the ML111-sensitive lung cancer cell lines, we posit that a downstream vulnerability (such as a synthetic lethal interaction) may be the target of ML111. Future target deconvolution studies will take these findings into account and utilize proteomic as well transcriptomic approaches for identifying the ML111 target(s) in these cells.

Cumulative data from our cell cycle analyses (arrest at or near G2/M), microtubule polymerization assays, and biochemical assessment of cell cycle associated proteins (cyclin B1, phosphorylation of histone (H3), and CDC20) collectively demonstrate that ML111 induces $\mathrm{M}$ phase arrest that is independent of a direct effect on microtubule polymerization. Chromatin condensation is a requisite event during mitosis and precedes the alignment of sister chromatids to the metaphase plate and eventually controlled the symmetrical segregation of sister chromatids during anaphase. Phosphorylation of histone H3 on serine 10 is strongly correlated with chromosomal condensation during cell division [42]; in our studies, $\mathrm{p}-\mathrm{H} 3^{\mathrm{Ser} 10}$ antibody staining of ML111 treated cells revealed condensed but unaligned chromatin. Additional mechanistic insight into the role of ML111 comes from global proteomic studies. These data revealed the accumulation of proteins that are targeted for degradation by the APC /C ubiquitin ligase complex in cells treated with ML111. Future studies will interrogate whether ML111 perturbs enzymatic activity of the APC /C complex by directly binding to target protein(s) or disrupting key protein-protein interactions critical for the function of this large protein complex.

The current standard of care treatment for Ewing's sarcoma relies on a multidisciplinary approach combining chemotherapy, surgery, and radiation therapy to control the primary tumors and limit metastasis [43]. Chemotherapy combinations include those involving vincristine (V), an inhibitor of microtubule polymerization; doxorubicin (D), a topoisomerase inhibitor; and cyclophosphamide (C), a DNA alkylating agent. The VDC treatment is alternatively cycled with ifosfamide, another DNA alkylating agent, and etoposide (a topoisomerase inhibitor) [44]. Several other combinatorial therapies for recurrent disease have been introduced, including gemcitabine plus docetaxel, irinotecan plus temozolomide [45], and topotecan and cyclophosphamide to optimize the balance between effectiveness and toxicity $[43,46]$. These chemotherapeutic regiments are largely non-selective and cytotoxic in nature, and despite intensive combination chemotherapeutic treatment approaches, the overall survival rates remain plateaued at $\sim 75 \%$ for primary disease and less than $30 \%$ for metastatic disease $[2,41,43]$.

Several active efforts for re-evaluating existing or investigate new anti-Ewing's sarcoma agents are ongoing [3,47]. A promising new compound is TK216, a small molecule that binds to EWS-FLI1, and by disrupting its interaction with RNA helicase A, it suppresses the downstream oncogenic transcriptional program to induce apoptosis and reduces tu- 
mor burden in Ewing's sarcoma cell and xenograft models [48]. TK216 is currently being evaluated as a single agent and in combination with vincristine in a phase I clinical trial (NCT02657005) for Ewing's sarcoma patients with relapsed or refectory disease [48].

Inhibitors of Insulin-like growth factor 1 receptor (IGF1R) and poly-(ADP-ribose) polymerase (PARP1) are also under investigation for treatment of Ewing's sarcoma [49,50]. Despite significant preclinical activity of an IGF1R inhibitor in Ewing's sarcoma models, the inhibitor and anti-IGF1R monoclonal antibodies cixutumumab and ganitumab have demonstrated only modest or partial response in a subset of patients [51], suggesting that a biomarker to predict responsiveness to IGF1R inhibition may be required for patient selection. While single-agent treatment with olaparib, a PARP1 inhibitor, effectively inhibited Ewing's sarcoma cell growth in vitro, monotherapy with olaparib failed to suppress Ewing's sarcoma xenograft tumor growth or provide survival advantage in vivo [50,52] and showed no clinical benefit in a phase II trial with continuous high-dose treatment as a single agent [50]. However, the combination of olaparib with temozolomide or irinotecan showed significant responses in $80 \%$ of mice orthotopically engrafted with human Ewing's sarcoma cells [52], and clinical trial data exploring combinations of PARP inhibitors in Ewing's sarcoma are pending. In a separate study, combination treatment involving olaparib and radiation amplified DNA damage in preclinical model of Ewing's sarcoma; however, the clinical benefits remain to be determined.

Nanoparticles have been extensively explored for the imaging and treatment of various cancers, including Ewing's sarcoma [53-56]. Biocompatible and biodegradable PEG-PCL nanoparticles play a particularly significant role in biomedical engineering and drug delivery fields [57]. Numerous preclinical studies validated that PEG-PCL nanoparticles are safe and do not induce acute and chronic toxicity in animals following single or multiple injections $[16,57,58]$. Moreover, PEG-PCL nanoparticles significantly enhance drug accumulation at the cancer site following systemic administration [40,57]. Our in vivo results demonstrate that the PEG-PCL nanoparticles described herein efficiently accumulate in and are retained by Ewing's sarcoma xenografts without the hallmarks of toxicity. Most importantly, our studies indicate that a nanoparticle-based ML111 formulation significantly inhibited SK-N-MC xenograft growth in vivo. Vincristine is one of the several chemotherapeutic drugs currently used to manage the disease (see above). In order to obtain the maximum therapeutic effect with minimal toxicity in the treatment of Ewing's sarcoma, we recently showed that ML111 can combine synergistically with vincristine to lower the dose required to inhibit xenograft tumor growth [53]. Of note, previous reports validated that PEG-PCL nanoparticles can be loaded with multiple drugs, allowing concurrent delivery of potentially synergistic chemotherapeutic combinations to tumors [40]. PEG-PCL nanoparticles can also be functionalized with various ligands (e.g., peptides, antibodies, etc.) to target one or more therapies to a particular tumor type [57].

\section{Conclusions}

In summary, we have demonstrated that ML111 inhibits growth and induces apoptosis of Ewing's sarcoma cells in vitro and suppresses growth of Ewing's sarcoma tumors in a mouse xenograft model without apparent toxicity. ML111 induces a pro-metaphase arrest of Ewing's sarcoma cells that may be associated with context-dependent inhibition of the APC/C complex, which harbors ubiquitin E3 ligase activity. We hypothesize that direct or indirect inhibition of the APC/C complex by ML111 results in the accumulation of multiple cell cycle proteins that must be degraded for progression through the G2/M checkpoint. Collectively, these actions result in enforcement of the spindle assembly checkpoint and initiation of an apoptotic response. The identification of the direct target of ML111 action should facilitate elucidation of the precise mechanism of ML111 action.

Supplementary Materials: The following are available online at https:/ / www.mdpi.com/article/ 10.3390/pharmaceutics13101553/s1, Figure S1: ML111 induced apoptosis in Ewing's sarcoma cell lines, Figure S2: Full-resolution cryo-TEM image of ML111-nanoparticles, Figure S3: Size distribution of ML111-NP as determined by dynamic light scattering, Figure S4: Fluorescence images of SK-N-MC 
cells treated with ML111-NP co-encapsulated with NIR SiNc dye, Figure S5: Effect of ML111-NP on total body mass, Figure S6: Quantification of immunohistochemical staining for $\mathrm{p}-\mathrm{H} 3^{\mathrm{Ser} 10}$ in sections of mouse xenograft, Figure S7: In vivo assessments of the acute toxicity of ML111-NP, Table S1: Effect of ML111 on viability of cancerous and primary cell lines, Table S2: Results of quantitative mass spectrometry analysis of the effect of ML111 on the SK-N-MC cell whole proteome, Table S3: Particle size (diameter), zeta potential, encapsulation efficacy, and loading capacity values of different polymer concentrations.

Author Contributions: Conceptualization, E.E.N., F.Y.S., W.K.V., M.N., O.T. (Oleh Taratula), M.A.D. and M.L.; methodology, E.E.N., F.Y.S., W.K.V., M.N., P.R.G. and O.T. (Olena Taratula); validation, E.E.N., F.Y.S., W.K.V., M.N., P.R.G., O.T. (Olena Taratula), O.T. (Oleh Taratula), M.A.D. and M.L.; formal analysis, E.E.N., F.Y.S., W.K.V., P.R.G., O.T. (Olena Taratula), O.T. (Oleh Taratula), M.A.D. and M.L.; investigation, E.E.N., F.Y.S., W.K.V., M.N., P.R.G., K.S.N. and M.A.D.; data curation, W.K.V.; writing—original draft preparation, E.E.N., F.Y.S., W.K.V., P.R.G., O.T. (Oleh Taratula), M.A.D. and M.L.; writing-review and editing, W.K.V., O.T. (Oleh Taratula), M.A.D. and M.L.; visualization, E.E.N., F.Y.S., W.K.V. and K.S.N.; supervision, O.T. (Olena Taratula), O.T. (Oleh Taratula), M.A.D. and M.L.; funding acquisition, P.R.G., O.T. (Oleh Taratula), M.A.D. and M.L. All authors have read and agreed to the published version of the manuscript.

Funding: This research was supported by awards from Oregon State University and Oregon Health and Science University, the National Cancer Institute of the National Institutes of Health (R01CA237569, R37CA234006, P30CA015704), the Oregon Center for Clinical and Translational Research, and the Sam Day Foundation. F.Y. Sabei was supported by a graduate fellowship from Jazan University. The Orbitrap Fusion mass spectrometer used in this research was funded by the M.J. Murdock Charitable Trust.

Institutional Review Board Statement: Animal studies were conducted with approval by the Institutional Animal Care and Use Committees of Oregon State University and Oregon Health and Sciences University (IP00000033, 29 June 2018).

Informed Consent Statement: Not applicable.

Data Availability Statement: Proteomics data have been deposited to the ProteomeXchange Consortium (http:/ / proteomecentral.proteomexchange.org (accessed on 12 August 2021)) via the MassIVE partner repository with the dataset identifier PXD023150 and can be downloaded from the following link: ftp:/ / massive.ucsd.edu/MSV000086599 (accessed on 12 August 2021).

Acknowledgments: The authors thank Robert Allan and Dylan Nelson for contributions to HTS experimental design and data analyses, C. Samuel Bradford for cell cycle data collection and analyses, and Brian Milless and Lisa Jones for assistance with proteomics experiments. Many of the established Ewing's sarcoma cell lines used herein were a generous gift from Marc Ladanyi at the Memorial Sloan Kettering Cancer Center.

Conflicts of Interest: The authors declare no conflict of interest.

\section{Appendix A}

Table A1. Quantification of proteins appearing in Figure 5A. Values are log2-fold relative downregulation (shades of blue) and upregulation (shades of red).

\begin{tabular}{|c|c|c|c|c|c|c|c|c|}
\hline 1.5 & 3 & 6 & 12 & $24 \mathrm{~h}$ & Protein & Uniprot Acc & $\begin{array}{c}\text { Gene } \\
\text { Symbol }\end{array}$ & $\begin{array}{c}\text { APC/C } \\
\text { Substrate } \\
\text { References }\end{array}$ \\
\hline \multicolumn{9}{|c|}{ Accumulating Cell Cycle Proteins } \\
\hline 0.29 & -0.21 & 0.38 & 0.74 & 1.96 & Borealin & Q53HL2 & CDCA8 & [59] \\
\hline 0.12 & 0.11 & 0.40 & 0.85 & 1.67 & SGO2 & Q562F6 & SGO2 & {$[60]$} \\
\hline 0.83 & 0.19 & 0.16 & 0.82 & 1.67 & Histone H3.2 & Q71DI3 & HIST2H3A & [61] \\
\hline 0.32 & -0.25 & 0.26 & 0.59 & 1.60 & GTSE1 & Q9NYZ3 & GTSE1 & {$[62]$} \\
\hline 0.27 & -0.39 & 0.27 & 0.68 & 1.59 & Survivin & O15392 & BIRC5 & [63] \\
\hline 0.34 & 0.02 & 0.33 & 0.59 & 1.56 & TACC3 & Q9Y6A5 & TACC3 & [64] \\
\hline 0.37 & -0.18 & 0.33 & 0.63 & 1.53 & NuSAP & Q9BXS6 & NUSAP1 & {$[65,66]$} \\
\hline
\end{tabular}


Table A1. Cont.

\begin{tabular}{|c|c|c|c|c|c|c|c|c|}
\hline 1.5 & 3 & 6 & 12 & $24 \mathrm{~h}$ & Protein & $\begin{array}{c}\text { Uniprot } \\
\text { Acc }\end{array}$ & $\begin{array}{c}\text { Gene } \\
\text { Symbol }\end{array}$ & $\begin{array}{c}\text { APC/C } \\
\text { Substrate } \\
\text { References }\end{array}$ \\
\hline 0.12 & -0.04 & 0.23 & 0.68 & 1.47 & INCENP & Q9NQS7 & INCENP & \\
\hline 0.12 & -0.04 & 0.26 & 0.47 & 1.43 & UBE2S & Q16763 & UBE2S & [67] \\
\hline 0.23 & -0.20 & 0.42 & 0.46 & 1.42 & Securin & O95997 & PTTG1 & {$[68,69]$} \\
\hline 0.13 & -0.03 & 0.41 & 0.71 & 1.38 & TPX2 & Q9ULW0 & TPX2 & [70] \\
\hline 0.09 & 0.26 & 0.46 & 0.76 & 1.34 & BUB1 & O43683 & BUB1 & [71] \\
\hline 0.37 & -0.29 & 0.15 & 0.34 & 1.22 & ZWINT & O95229 & ZWINT & [72] \\
\hline 0.23 & -0.13 & 0.28 & 0.38 & 1.21 & Tome-1 & Q99618 & CDCA3 & [73] \\
\hline 0.81 & 0.34 & 0.36 & 0.75 & 1.16 & LSM14B-var & A0A0C4DFV2 & LSM14B & [60] \\
\hline 0.08 & -0.05 & 0.15 & 0.33 & 1.12 & HURP & Q15398 & DLGAP5 & [66] \\
\hline 0.25 & 0.18 & 0.39 & 0.53 & 1.10 & HMMR & O75330 & HMMR & [66] \\
\hline 0.05 & -0.19 & 0.23 & 0.46 & 1.09 & PIMREG & Q9BSJ6 & PIMREG & [74] \\
\hline 0.08 & 0.00 & 0.13 & 0.43 & 1.05 & $\mathrm{Ki}-67$ & P46013 & MKI67 & [75] \\
\hline-0.26 & 0.41 & 0.52 & 0.83 & 1.00 & Cyclin B1 & P14635 & CCNB1 & [76] \\
\hline 0.06 & 0.14 & 0.31 & 0.51 & 1.00 & PRC1 & O43663 & PRC1 & [77-79] \\
\hline 0.02 & 0.15 & 0.35 & 0.57 & 0.97 & CENP-E & P04183 & TK1 & [80] \\
\hline-0.06 & 0.08 & 0.21 & 0.49 & 0.97 & TK1 & Q02224 & CENPE & [81] \\
\hline-0.11 & 0.15 & 0.30 & 0.55 & 0.96 & Anillin & Q9NQW6 & ANLN & [82] \\
\hline-0.27 & 0.26 & 0.39 & 0.72 & 0.95 & Aurora A & O14965 & AURKA & [83] \\
\hline-0.25 & 0.34 & 0.36 & 0.68 & 0.95 & Aurora B & Q96GD4 & AURKB & [84] \\
\hline 0.40 & -0.01 & 0.24 & 0.66 & 0.94 & Sororin & B5MBX0 & CDCA5 & {$[85,86]$} \\
\hline 0.00 & 0.15 & 0.32 & 0.51 & 0.91 & CENP-F & P49454 & CENPF & [81] \\
\hline-0.09 & 0.24 & 0.37 & 0.57 & 0.89 & KIFC1 & Q9BW19 & KIFC1 & [87] \\
\hline 0.09 & 0.10 & 0.29 & 0.53 & 0.87 & CKAP2 & Q8WWK9 & CKAP2 & [88] \\
\hline-0.07 & -0.04 & 0.04 & 0.48 & 0.85 & Repo-Man & Q69YH5 & CDCA2 & [89] \\
\hline 0.52 & -0.33 & 0.38 & 0.50 & 0.84 & Geminin & O75496 & GMNN & [90] \\
\hline 0.16 & -0.04 & 0.34 & 0.67 & 0.83 & CDC20 & Q12834 & CDC20 & [62] \\
\hline-0.02 & -0.04 & 0.22 & 0.35 & 0.83 & Spindly & Q96EA4 & SPDL1 & \\
\hline 0.05 & -0.24 & 0.14 & 0.24 & 0.82 & UBE2C & O00762 & UBE2C & {$[91,92]$} \\
\hline 0.04 & 0.19 & 0.32 & 0.57 & 0.81 & KIF18A & Q99661 & KIF2C & [87] \\
\hline-0.20 & 0.13 & 0.24 & 0.46 & 0.81 & KIF2C & Q8NI77 & KIF18A & [93] \\
\hline 0.07 & 0.12 & 0.33 & 0.62 & 0.80 & KIF22 & Q14807 & KIF22 & [94] \\
\hline-0.35 & 0.19 & 0.22 & 0.50 & 0.80 & KIF20A & O95235 & KIF20A & [74] \\
\hline-0.24 & 0.35 & 0.34 & 0.60 & 0.73 & PLK1 & P53350 & PLK1 & [95] \\
\hline-0.58 & 0.26 & 0.12 & 0.49 & 0.71 & Top2 $\alpha$ & P11388 & TOP2A & [96] \\
\hline 0.45 & -0.25 & 0.09 & 0.16 & 0.70 & LSM14B & Q9BX40 & LSM14B & [60] \\
\hline 0.49 & -0.21 & 0.11 & 0.15 & 0.65 & UPF3B & Q9BZI7 & UPF3B & [60] \\
\hline-0.38 & 0.19 & 0.20 & 0.48 & 0.59 & ECT2 & Q9H8V3 & ECT2 & {$[88,97]$} \\
\hline \multicolumn{9}{|c|}{ Non-accumulating Prophase APC/C substrates } \\
\hline 0.28 & 0.06 & 0.29 & -0.01 & 0.33 & HOXC10 & Q9NYD6 & HOXC10 & [36] \\
\hline-0.18 & -0.04 & 0.37 & 0.30 & -0.49 & Cyclin A2 & P20248 & CCNA2 & [35] \\
\hline
\end{tabular}

\section{References}

1. Smith, M.A.; Altekruse, S.F.; Adamson, P.C.; Reaman, G.H.; Seibel, N.L. Declining Childhood and Adolescent Cancer Mortality. Cancer 2014, 120, 2497-2506. [CrossRef]

2. Riggi, N.; Suvà, M.L.; Stamenkovic, I. Ewing's Sarcoma. N. Engl. J. Med. 2021, 384, 154-164. [CrossRef]

3. Bailey, K.; Cost, C.; Davis, I.; Glade-Bender, J.; Grohar, P.; Houghton, P.; Isakoff, M.; Stewart, E.; Laack, N.; Yustein, J.; et al. Emerging Novel Agents for Patients with Advanced Ewing Sarcoma: A Report from the Children's Oncology Group (COG) New Agents for Ewing Sarcoma Task Force. F1000Research 2019, 8, 493. [CrossRef]

4. Womer, R.B.; West, D.C.; Krailo, M.D.; Dickman, P.S.; Pawel, B.R.; Grier, H.E.; Marcus, K.; Sailer, S.; Healey, J.H.; Dormans, J.P.; et al. Randomized Controlled Trial of Interval-Compressed Chemotherapy for the Treatment of Localized Ewing Sarcoma: A Report from the Children's Oncology Group. J. Clin. Oncol. 2012, 30, 4148-4154. [CrossRef]

5. Lessnick, S.L.; Braun, B.S.; Denny, C.T.; May, W.A. Multiple Domains Mediate Transformation by the Ewing's Sarcoma EWS/FLI-1 Fusion Gene. Oncogene 1995, 10, 423-431.

6. Toomey, E.C.; Schiffman, J.D.; Lessnick, S.L. Recent Advances in the Molecular Pathogenesis of Ewing's Sarcoma. Oncogene 2010, 29, 4504-4516. [CrossRef] [PubMed] 
7. May, W.A.; Lessnick, S.L.; Braun, B.S.; Klemsz, M.; Lewis, B.C.; Lunsford, L.B.; Hromas, R.; Denny, C.T. The Ewing's Sarcoma EWS/FLI-1 Fusion Gene Encodes a More Potent Transcriptional Activator and Is a More Powerful Transforming Gene Than FLI-1. Mol. Cell. Biol. 1993, 13, 7393-7398. [CrossRef] [PubMed]

8. Lessnick, S.L.; Ladanyi, M. Molecular Pathogenesis of Ewing Sarcoma: New Therapeutic and Transcriptional Targets. Annu. Rev. Pathol. 2012, 7, 145-159. [CrossRef] [PubMed]

9. Smith, R.; Owen, L.A.; Trem, D.J.; Wong, J.S.; Whangbo, J.S.; Golub, T.R.; Lessnick, S.L. Expression Profiling of EWS/FLI Identifies NKX2.2 as a Critical Target Gene in Ewing's Sarcoma. Cancer Cell 2006, 9, 405-416. [CrossRef]

10. Prieur, A.; Tirode, F.; Cohen, P.; Delattre, O. EWS/FLI-1 Silencing and Gene Profiling of Ewing Cells Reveal Downstream Oncogenic Pathways and a Crucial Role for Repression of Insulin-Like Growth Factor Binding Protein 3. Mol. Cell. Biol. 2004, 24, 7275-7283. [CrossRef]

11. Minas, T.Z.; Surdez, D.; Javaheri, T.; Tanaka, M.; Howarth, M.; Kang, H.-J.; Han, J.; Han, Z.-Y.; Sax, B.; Kream, B.E.; et al. Combined Experience of Six Independent Laboratories Attempting to Create an Ewing Sarcoma Mouse Model. Oncotarget 2017, 8, 34141-34163. [CrossRef] [PubMed]

12. Riggi, N.; Cironi, L.; Provero, P.; Suvà, M.-L.; Kaloulis, K.; Garcia-Echeverria, C.; Hoffmann, F.; Trumpp, A.; Stamenkovic, I. Development of Ewing's Sarcoma from Primary Bone Marrow-Derived Mesenchymal Progenitor Cells. Cancer Res. 2005, 65, 11459-11468. [CrossRef]

13. Üren, A.; Toretsky, J.A. Ewing's Sarcoma Oncoprotein EWS-FLI1: The Perfect Target without a Therapeutic Agent. Future Oncol. 2005, 1, 521-528. [CrossRef]

14. Dgachi, Y.; Bautista-Aguilera, O.M.; Benchekroun, M.; Martin, H.; Bonet, A.; Knez, D.; Godyń, J.; Malawska, B.; Gobec, S.; Chioua, M.; et al. Synthesis and Biological Evaluation of Benzochromenopyrimidinones as Cholinesterase Inhibitors and Potent Antioxidant, Non-Hepatotoxic Agents for Alzheimer's Disease. Molecules 2016, 21, 634. [CrossRef] [PubMed]

15. Zhang, J.; Chung, T.; Oldenburg, K. A Simple Statistical Parameter for Use in Evaluation and Validation of High Throughput Screening Assays. J. Biomol. Screen. 1999, 4, 67-73. [CrossRef]

16. Albarqi, H.A.; Wong, L.H.; Schumann, C.; Sabei, F.Y.; Korzun, T.; Li, X.; Hansen, M.N.; Dhagat, P.; Moses, A.S.; Taratula, O.; et al. Biocompatible Nanoclusters with High Heating Efficiency for Systemically Delivered Magnetic Hyperthermia. ACS Nano 2019, 13, 6383-6395. [CrossRef] [PubMed]

17. Mellacheruvu, D.; Wright, Z.; Couzens, A.L.; Lambert, J.-P.; St-Denis, N.A.; Li, T.; Miteva, Y.V.; Hauri, S.; Sardiu, M.E.; Low, T.Y.; et al. The CRAPome: A Contaminant Repository for Affinity Purification-Mass Spectrometry Data. Nat. Methods 2013, 10, 730-736. [CrossRef]

18. Eng, J.K.; McCormack, A.L.; Yates, J.R. An Approach to Correlate Tandem Mass Spectral Data of Peptides with Amino Acid Sequences in a Protein Database. J. Am. Soc. Mass Spectrom. 1994, 5, 976-989. [CrossRef]

19. Käll, L.; Canterbury, J.D.; Weston, J.; Noble, W.S.; MacCoss, M.J. Semi-Supervised Learning for Peptide Identification from Shotgun Proteomics Datasets. Nat. Methods 2007, 4, 923-925. [CrossRef]

20. Li, X.; Schumann, C.; Albarqi, H.A.; Lee, C.J.; Alani, A.W.G.; Bracha, S.; Milovancev, M.; Taratula, O.; Taratula, O. A TumorActivatable Theranostic Nanomedicine Platform for NIR Fluorescence-Guided Surgery and Combinatorial Phototherapy. Theranostics 2018, 8, 767-784. [CrossRef]

21. Shin, H.-C.; Alani, A.W.G.; Cho, H.; Bae, Y.; Kolesar, J.M.; Kwon, G.S. A 3-in-1 Polymeric Micelle Nanocontainer for Poorly Water-Soluble Drugs. Mol. Pharm. 2011, 8, 1257-1265. [CrossRef] [PubMed]

22. Marquardt, D.W. An Algorithm for Least-Squares Estimation of Nonlinear Parameters. J. Soc. Ind. Appl. Math. 1963, 11, 431-441. [CrossRef]

23. Taratula, O.; Dani, R.K.; Schumann, C.; Xu, H.; Wang, A.; Song, H.; Dhagat, P.; Taratula, O. Multifunctional Nanomedicine Platform for Concurrent Delivery of Chemotherapeutic Drugs and Mild Hyperthermia to Ovarian Cancer Cells. Int. J. Pharm. 2013, 458, 169-180. [CrossRef] [PubMed]

24. Giovannini, M.; Biegel, J.A.; Serra, M.; Wang, J.Y.; Wei, Y.H.; Nycum, L.; Emanuel, B.S.; Evans, G.A. Ews-Erg and EWS-Fli1 Fusion Transcripts in Ewing's Sarcoma and Primitive Neuroectodermal Tumors with Variant Translocations. J. Clin. Investig. 1994, 94, 489-496. [CrossRef] [PubMed]

25. Lin, P.P.; Brody, R.I.; Hamelin, A.C.; Bradner, J.E.; Healey, J.H.; Ladanyi, M. Differential Transactivation by Alternative EWS-FLI1 Fusion Proteins Correlates with Clinical Heterogeneity in Ewing's Sarcoma. Cancer Res. 1999, 59, 1428-1432. [PubMed]

26. Lipinski, C.A.; Lombardo, F.; Dominy, B.W.; Feeney, P.J. Experimental and Computational Approaches to Estimate Solubility and Permeability in Drug Discovery and Development Settings. Adv. Drug Deliv. Rev. 2001, 46, 3-26. [CrossRef]

27. Li, J.; Yuan, J. Caspases in Apoptosis and Beyond. Oncogene 2008, 27, 6194-6206. [CrossRef] [PubMed]

28. Fischer, U.; Jänicke, R.U.; Schulze-Osthoff, K. Many Cuts to Ruin: A Comprehensive Update of Caspase Substrates. Cell Death Differ. 2003, 10, 76-100. [CrossRef]

29. Kaufmann, S.H.; Desnoyers, S.; Ottaviano, Y.; Davidson, N.E.; Poirier, G.G. Specific Proteolytic Cleavage of Poly (ADP-Ribose) Polymerase: An Early Marker of Chemotherapy-Induced Apoptosis. Cancer Res. 1993, 53, 3976-3985.

30. Murray, A.W. Recycling the Cell Cycle: Cyclins Revisited. Cell 2004, 116, 221-234. [CrossRef]

31. Glotzer, M.; Murray, A.W.; Kirschner, M.W. Cyclin Is Degraded by the Ubiquitin Pathway. Nature 1991, 349, 132-138. [CrossRef] [PubMed] 
32. Prinz, S.; Hwang, E.S.; Visintin, R.; Amon, A. The Regulation of Cdc20 Proteolysis Reveals a Role for APC Components Cdc23 and Cdc27 During S Phase and Early Mitosis. Curr. Biol. 1998, 8, 750-760. [CrossRef]

33. Prigent, C.; Dimitrov, S. Phosphorylation of Serine 10 in Histone H3, What for? J. Cell Sci. 2003, 116, 3677-3685. [CrossRef] [PubMed]

34. Xie, C.-M.; Lin, X.-T.; Wu, D.; Tan, Y.; Cheng, C.H.K.; Zhang, J. Cardiac Glycoside Bufalin Blocks Cancer Cell Growth by Inhibition of Aurora a and Aurora B Activation via PI3K-Akt Pathway. Oncotarget 2018, 9, 13783-13795. [CrossRef]

35. Den Elzen, N.; Pines, J. Cyclin a Is Destroyed in Prometaphase and Can Delay Chromosome Alignment and Anaphase. J. Cell Biol. 2001, 153, 121-136. [CrossRef] [PubMed]

36. Gabellini, D.; Colaluca, I.N.; Vodermaier, H.C.; Biamonti, G.; Giacca, M.; Falaschi, A.; Riva, S.; Peverali, F.A. Early Mitotic Degradation of the Homeoprotein HOXC10 Is Potentially Linked to Cell Cycle Progression. EMBO J. 2003, 22, 3715-3724. [CrossRef]

37. Hames, R.S.; Wattam, S.L.; Yamano, H.; Bacchieri, R.; Fry, A.M. APC/C-Mediated Destruction of the Centrosomal Kinase Nek2A Occurs in Early Mitosis and Depends upon a Cyclin a-Type D-Box. EMBO J. 2001, 20, 7117-7127. [CrossRef]

38. Taratula, O.; Doddapaneni, B.S.; Schumann, C.; Li, X.; Bracha, S.; Milovancev, M.; Alani, A.W.G.; Taratula, O. NaphthalocyanineBased Biodegradable Polymeric Nanoparticles for Image-Guided Combinatorial Phototherapy. Chem. Mater. 2015, 27, 6155-6165. [CrossRef]

39. Lee, J.H.; Yeo, Y. Controlled Drug Release from Pharmaceutical Nanocarriers. Chem. Eng. Sci. 2015, 125, 75-84. [CrossRef]

40. Doddapaneni, B.S.; Kyryachenko, S.; Chagani, S.E.; Alany, R.G.; Rao, D.A.; Indra, A.K.; Alani, A.W.G. A Three-Drug Nanoscale Drug Delivery System Designed for Preferential Lymphatic Uptake for the Treatment of Metastatic Melanoma. J. Control. Release 2015, 220, 503-514. [CrossRef]

41. Pishas, K.I.; Lessnick, S.L. Recent Advances in Targeted Therapy for Ewing Sarcoma. F1000Research 2016, 5, 2077. [CrossRef]

42. Hans, F.; Dimitrov, S. Histone H3 Phosphorylation and Cell Division. Oncogene 2001, 20, 3021-3027. [CrossRef]

43. Gaspar, N.; Hawkins, D.S.; Dirksen, U.; Lewis, I.J.; Ferrari, S.; Le Deley, M.-C.; Kovar, H.; Grimer, R.; Whelan, J.; Claude, L.; et al. Ewing Sarcoma: Current Management and Future Approaches through Collaboration. J. Clin. Oncol. 2015, 33, 3036-3046. [CrossRef] [PubMed]

44. Robertson, J.; Barr, R.; Shulman, L.N.; Forte, G.B.; Magrini, N. Essential Medicines for Cancer: WHO Recommendations and National Priorities. Bull. World Health Organ. 2016, 94, 735-742. [CrossRef]

45. Casey, D.A.; Wexler, L.H.; Merchant, M.S.; Chou, A.J.; Merola, P.R.; Price, A.P.; Meyers, P.A. Irinotecan and Temozolomide for Ewing Sarcoma: The Memorial Sloan-Kettering Experience. Pediatr. Blood Cancer 2009, 53, 1029-1034. [CrossRef]

46. Hunold, A.; Weddeling, N.; Paulussen, M.; Ranft, A.; Liebscher, C.; Jürgens, H. Topotecan and Cyclophosphamide in Patients with Refractory or Relapsed Ewing Tumors. Pediatr. Blood Cancer 2006, 47, 795-800. [CrossRef] [PubMed]

47. Grohar, P.J.; Helman, L.J. Prospects and Challenges for the Development of New Therapies for Ewing Sarcoma. Pharmacol. Ther. 2013, 137, 216-224. [CrossRef] [PubMed]

48. Erkizan, H.V.; Kong, Y.; Merchant, M.; Schlottmann, S.; Barber-Rotenberg, J.S.; Yuan, L.; Abaan, O.D.; Chou, T.-H.; Dakshanamurthy, S.; Brown, M.L.; et al. A Small Molecule Blocking Oncogenic Protein EWS-FLI1 Interaction with RNA Helicase a Inhibits Growth of Ewing's Sarcoma. Nat. Med. 2009, 15, 750-756. [CrossRef]

49. Van Maldegem, A.M.; Bovée, J.V.M.G.; Peterse, E.F.P.; Hogendoorn, P.C.W.; Gelderblom, H. Ewing Sarcoma: The Clinical Relevance of the Insulin-Like Growth Factor 1 and the Poly-ADP-Ribose-Polymerase Pathway. Eur. J. Cancer 2016, 53, 171-180. [CrossRef]

50. Vormoor, B.; Curtin, N.J. Poly (ADP-Ribose) Polymerase Inhibitors in Ewing Sarcoma. Curr. Opin. Oncol. 2014, 26, 428-433. [CrossRef]

51. Schwartz, G.K.; Tap, W.D.; Qin, L.-X.; Livingston, M.B.; Undevia, S.D.; Chmielowski, B.; Agulnik, M.; Schuetze, S.M.; Reed, D.R.; Okuno, S.H.; et al. Cixutumumab and Temsirolimus for Patients with Bone and Soft-Tissue Sarcoma: A Multicentre, Open-Label, Phase 2 Trial. Lancet Oncol. 2013, 14, 371-382. [CrossRef]

52. Stewart, E.; Goshorn, R.; Bradley, C.; Griffiths, L.M.; Benavente, C.; Twarog, N.R.; Miller, G.M.; Caufield, W.; Freeman, B.B.; Bahrami, A.; et al. Targeting the DNA Repair Pathway in Ewing Sarcoma. Cell Rep. 2014, 9, 829-841. [CrossRef] [PubMed]

53. Sabei, F.Y.; Taratula, O.; Albarqi, H.A.; Al-Fatease, A.M.; Moses, A.S.; Demessie, A.A.; Park, Y.; Vogel, W.K.; Esfandiari Nazzaro, E.; Davare, M.A.; et al. A Targeted Combinatorial Therapy for Ewing's Sarcoma. Nanomedicine 2021, 37, 102446. [CrossRef]

54. Yang, S.; Wallach, M.; Krishna, A.; Kurmasheva, R.; Sridhar, S. Recent Developments in Nanomedicine for Pediatric Cancer. J. Clin. Med. 2021, 10. [CrossRef] [PubMed]

55. Zeng, L.; Su, Z.; Li, X.; Shi, S. Construction of Triblock Copolymer-Gold Nanorod Composites for Fluorescence Resonance Energy Transfer via pH-Sensitive Allosteric. Chin. Chem. Lett. 2020, 31, 3131-3134. [CrossRef]

56. Xu, J.; Shang, L. Emerging Applications of Near-Infrared Fluorescent Metal Nanoclusters for Biological Imaging. Chin. Chem. Lett. 2018, 29, 1436-1444. [CrossRef]

57. Grossen, P.; Witzigmann, D.; Sieber, S.; Huwyler, J. PEG-PCL-Based Nanomedicines: A Biodegradable Drug Delivery System and Its Application. J. Control. Release 2017, 260, 46-60. [CrossRef] [PubMed]

58. Moses, A.S.; Taratula, O.R.; Lee, H.; Luo, F.; Grenz, T.; Korzun, T.; Lorenz, A.S.; Sabei, F.Y.; Bracha, S.; Alani, A.W.G.; et al. Nanoparticle-Based Platform for Activatable Fluorescence Imaging and Photothermal Ablation of Endometriosis. Small 2020, 16, e1906936. [CrossRef] 
59. Tsunematsu, T.; Arakaki, R.; Kawai, H.; Ruppert, J.; Tsuneyama, K.; Ishimaru, N.; Earnshaw, W.C.; Pagano, M.; Kudo, Y. APC/CCdh1 Is Required for the Termination of Chromosomal Passenger Complex Activity Upon Mitotic Exit. J. Cell Sci. 2020, 133. [CrossRef] [PubMed]

60. Bakos, G.; Yu, L.; Gak, I.A.; Roumeliotis, T.I.; Liakopoulos, D.; Choudhary, J.S.; Mansfeld, J. An E2-Ubiquitin Thioester-Driven Approach to Identify Substrates Modified with Ubiquitin and Ubiquitin-Like Molecules. Nat. Commun. 2018, 9, 4776. [CrossRef]

61. Oh, E.; Mark, K.G.; Mocciaro, A.; Watson, E.R.; Prabu, J.R.; Cha, D.D.; Kampmann, M.; Gamarra, N.; Zhou, C.Y.; Rape, M. Gene Expression and Cell Identity Controlled by Anaphase-Promoting Complex. Nature 2020, 579, 136-140. [CrossRef]

62. Pfleger, C.M.; Kirschner, M.W. The KEN Box: An APC Recognition Signal Distinct from the D Box Targeted by Cdh1. Genes Dev. 2000, 14, 655-665. [PubMed]

63. Pines, J. Mitosis: A Matter of Getting Rid of the Right Protein at the Right Time. Trends Cell Biol. 2006, 16, 55-63. [CrossRef] [PubMed]

64. Jeng, J.-C.; Lin, Y.-M.; Lin, C.-H.; Shih, H.-M. Cdh1 Controls the Stability of TACC3. Cell Cycle 2009, 8, 3537-3544. [CrossRef]

65. Li, L.; Zhou, Y.; Sun, L.; Xing, G.; Tian, C.; Sun, J.; Zhang, L.; He, F. NuSAP Is Degraded by APC/C-Cdh1 and Its Overexpression Results in Mitotic Arrest Dependent of Its Microtubules' Affinity. Cell. Signal. 2007, 19, 2046-2055. [CrossRef] [PubMed]

66. Song, L.; Rape, M. Regulated Degradation of Spindle Assembly Factors by the Anaphase-Promoting Complex. Mol. Cell 2010, 38, 369-382. [CrossRef] [PubMed]

67. Williamson, A.; Wickliffe, K.E.; Mellone, B.G.; Song, L.; Karpen, G.H.; Rape, M. Identification of a Physiological E2 Module for the Human Anaphase-Promoting Complex. Proc. Natl. Acad. Sci. USA 2009, 106, 18213-18218. [CrossRef]

68. Zou, H.; McGarry, T.J.; Bernal, T.; Kirschner, M.W. Identification of a Vertebrate Sister-Chromatid Separation Inhibitor Involved in Transformation and Tumorigenesis. Science 1999, 285, 418-422. [CrossRef]

69. Hagting, A.; Den Elzen, N.; Vodermaier, H.C.; Waizenegger, I.C.; Peters, J.-M.; Pines, J. Human Securin Proteolysis Is Controlled by the Spindle Checkpoint and Reveals When the APC/C Switches from Activation by Cdc20 to Cdh1. J. Cell Biol. 2002, 157, 1125-1137. [CrossRef]

70. Stewart, S.; Fang, G. Anaphase-Promoting Complex/Cyclosome Controls the Stability of TPX2 During Mitotic Exit. Mol. Cell. Biol. 2005, 25, 10516-10527. [CrossRef]

71. Qi, W.; Yu, H. KEN-Box-Dependent Degradation of the Bub1 Spindle Checkpoint Kinase by the Anaphase-Promoting Complex/Cyclosome. J. Biol. Chem. 2007, 282, 3672-3679. [CrossRef] [PubMed]

72. He, Y.; Li, R.; Gu, L.; Deng, H.; Zhao, Y.; Guo, Y.; Yu, S.; Wang, G. Anaphase-Promoting Complex/Cyclosome-Cdc-20 Promotes Zwint-1 Degradation. Cell Biochem. Funct. 2020, 38, 451-459. [CrossRef] [PubMed]

73. Ayad, N.G.; Rankin, S.; Murakami, M.; Jebanathirajah, J.; Gygi, S.; Kirschner, M.W. Tome-1, a Trigger of Mitotic Entry, Is Degraded during G1 via the APC. Cell 2003, 113, 101-113. [CrossRef]

74. Zhao, W.-M.; Coppinger, J.A.; Seki, A.; Cheng, X.-L.; Yates, J.R.; Fang, G. RCS1, a Substrate of APC/C, Controls the Metaphase to Anaphase Transition. Proc. Natl. Acad. Sci. USA 2008, 105, 13415-13420. [CrossRef]

75. Sobecki, M.; Mrouj, K.; Colinge, J.; Gerbe, F.; Jay, P.; Krasinska, L.; Dulic, V.; Fisher, D. Cell-Cycle Regulation Accounts for Variability in Ki-67 Expression Levels. Cancer Res. 2017, 77, 2722-2734. [CrossRef] [PubMed]

76. Clute, P.; Pines, J. Temporal and Spatial Control of Cyclin B1 Destruction in Metaphase. Nat. Cell Biol. 1999, 1, 82-87. [CrossRef]

77. Juang, Y.L.; Huang, J.; Peters, J.M.; McLaughlin, M.E.; Tai, C.Y.; Pellman, D. APC-Mediated Proteolysis of Ase1 and the Morphogenesis of the Mitotic Spindle. Science 1997, 275, 1311-1314. [CrossRef]

78. Visintin, R.; Prinz, S.; Amon, A. CDC20 and CDH1: A Family of Substrate-Specific Activators of APC-Dependent Proteolysis. Science 1997, 278, 460-463. [CrossRef]

79. Castro, A.; Bernis, C.; Vigneron, S.; Labbé, J.-C.; Lorca, T. The Anaphase-Promoting Complex: A Key Factor in the Regulation of Cell Cycle. Oncogene 2005, 24, 314-325. [CrossRef]

80. Ke, P.-Y.; Chang, Z.-F. Mitotic Degradation of Human Thymidine Kinase 1 Is Dependent on the Anaphase-Promoting Complex/Cyclosome-CDH1-Mediated Pathway. Mol. Cell. Biol. 2004, 24, 514-526. [CrossRef]

81. Gurden, M.D.J.; Holland, A.J.; van Zon, W.; Tighe, A.; Vergnolle, M.A.; Andres, D.A.; Spielmann, H.P.; Malumbres, M.; Wolthuis, R.M.F.; Cleveland, D.W.; et al. Cdc20 Is Required for the Post-Anaphase, KEN-Dependent Degradation of Centromere Protein F. J. Cell Sci. 2010, 123, 321-330. [CrossRef]

82. Zhao, W.-M.; Fang, G. Anillin Is a Substrate of Anaphase-Promoting Complex/Cyclosome (APC/C) That Controls Spatial Contractility of Myosin During Late Cytokinesis. J. Biol. Chem. 2005, 280, 33516-33524. [CrossRef]

83. Floyd, S.; Pines, J.; Lindon, C. APC/C Cdh1 Targets Aurora Kinase to Control Reorganization of the Mitotic Spindle at Anaphase. Curr. Biol. 2008, 18, 1649-1658. [CrossRef] [PubMed]

84. Stewart, S.; Fang, G. Destruction Box-Dependent Degradation of Aurora B Is Mediated by the Anaphase-Promoting Complex/Cyclosome and Cdh1. Cancer Res. 2005, 65, 8730-8735. [CrossRef]

85. Rankin, S.; Ayad, N.G.; Kirschner, M.W. Sororin, a Substrate of the Anaphase-Promoting Complex, Is Required for Sister Chromatid Cohesion in Vertebrates. Mol. Cell 2005, 18, 185-200. [CrossRef]

86. Zhang, N.; Pati, D. Sororin Is a Master Regulator of Sister Chromatid Cohesion and Separation. Cell Cycle 2012, 11, 2073-2083. [CrossRef] [PubMed]

87. Singh, S.A.; Winter, D.; Kirchner, M.; Chauhan, R.; Ahmed, S.; Ozlu, N.; Tzur, A.; Steen, J.A.; Steen, H. Co-Regulation Proteomics Reveals Substrates and Mechanisms of APC/C-Dependent Degradation. EMBO J. 2014, 33, 385-399. [CrossRef] [PubMed] 
88. Seki, A.; Fang, G. CKAP2 Is a Spindle-Associated Protein Degraded by APC/C-Cdh1 During Mitotic Exit. J. Biol. Chem. 2007, 282, 15103-15113. [CrossRef]

89. Manzione, M.G.; Rombouts, J.; Steklov, M.; Pasquali, L.; Sablina, A.; Gelens, L.; Qian, J.; Bollen, M. Co-Regulation of the Antagonistic RepoMan:Aurora-B Pair in Proliferating Cells. Mol. Biol. Cell 2020, 31, 419-438. [CrossRef] [PubMed]

90. McGarry, T.J.; Kirschner, M.W. Geminin, an Inhibitor of DNA Replication, Is Degraded During Mitosis. Cell 1998, 93, 1043-1053. [CrossRef]

91. Rape, M.; Kirschner, M.W. Autonomous Regulation of the Anaphase-Promoting Complex Couples Mitosis to S-Phase Entry. Nature 2004, 432, 588-595. [CrossRef]

92. Rape, M.; Reddy, S.K.; Kirschner, M.W. The Processivity of Multiubiquitination by the APC Determines the Order of Substrate Degradation. Cell 2006, 124, 89-103. [CrossRef]

93. Sedgwick, G.G.; Hayward, D.G.; Di Fiore, B.; Pardo, M.; Yu, L.; Pines, J.; Nilsson, J. Mechanisms Controlling the Temporal Degradation of Nek2A and Kif18A by the APC/C-Cdc20 Complex. EMBO J. 2013, 32, 303-314. [CrossRef] [PubMed]

94. Feine, O.; Zur, A.; Mahbubani, H.; Brandeis, M. Human Kid Is Degraded by the APC/C(Cdh1) but Not by the APC/C(Cdc20) Cell Cycle 2007, 6, 2516-2523. [CrossRef]

95. Lindon, C.; Pines, J. Ordered Proteolysis in Anaphase Inactivates Plk1 to Contribute to Proper Mitotic Exit in Human Cells. J. Cell Biol. 2004, 164, 233-241. [CrossRef] [PubMed]

96. Eguren, M.; Álvarez-Fernández, M.; García, F.; López-Contreras, A.J.; Fujimitsu, K.; Yaguchi, H.; Luque-García, J.L.; Fernández-Capetillo, O.; Munoz, J.; Yamano, H.; et al. A Synthetic Lethal Interaction Between APC/C and Topoisomerase Poisons Uncovered by Proteomic Screens. Cell Rep. 2014, 6, 670-683. [CrossRef] [PubMed]

97. Liot, C.; Seguin, L.; Siret, A.; Crouin, C.; Schmidt, S.; Bertoglio, J. APC(Cdh1) Mediates Degradation of the Oncogenic Rho-GEF Ect2 After Mitosis. PLoS ONE 2011, 6, e23676. [CrossRef] [PubMed] 